\title{
The agricultural impact of the 2015-2016 floods in Ireland as mapped through Sentinel 1 satellite imagery
}

\author{
R. O'Hara ${ }^{1,2 \dagger}$, S. Green ${ }^{1}$, T. McCarthy ${ }^{2}$
}

${ }^{1}$ Teagasc, Ashtown Food Research Centre, Ashtown, Dublin, Ireland

${ }^{2}$ National Centre for Geocomputation, Maynooth University, Maynooth, Kildare, Ireland

Abstract

The capability of Sentinel $1 \mathrm{C}$-band ( $5 \mathrm{~cm}$ wavelength) synthetic aperture radio detection and ranging (RADAR) (abbreviated as SAR) for flood mapping is demonstrated, and this approach is used to map the extent of the extensive floods that occurred throughout the Republic of Ireland in the winter of 2015-2016. Thirty-three Sentinel 1 images were used to map the area and duration of floods over a 6-mo period from November 2015 to April 2016. Flood maps for 11 separate dates charted the development and persistence of floods nationally. The maximum flood extent during this period was estimated to be $\sim 24,356$ ha. The depth of rainfall influenced the magnitude of flood in the preceding $5 \mathrm{~d}$ and over more extended periods to a lesser degree. Reduced photosynthetic activity on farms affected by flooding was observed in Landsat 8 vegetation index difference images compared to the previous spring. The accuracy of the flood map was assessed against reports of flooding from affected farms, as well as other satellite-derived maps from Copernicus Emergency Management Service and Sentinel 2. Monte Carlo simulated elevation data $(20 \mathrm{~m}$ resolution, $2.5 \mathrm{~m}$ root mean square error [RMSE]) were used to estimate the flood's depth and volume. Although the modelled flood height showed a strong correlation with the measured river heights, differences of several metres were observed. Future mapping strategies are discussed, which include high-temporal-resolution soil moisture data, as part of an integrated multisensor approach to flood response over Keywords a range of spatial scales.

Agriculture $\bullet$ flooding $\bullet$ Landsat $\bullet$ mitigation $\cdot$ remote sensing $\bullet$ Sentinel

\section{Introduction}

In the winter of 2015-2016, the British Isles were struck by a series of devastating storms, which brought extensive and persistent flooding to many areas. In the Republic of Ireland, the volume of seasonal precipitation was unprecedented. Three major winter storms in December 2015 (storms Desmond, Eva and Frank) resulted in $>50 \%$ of synoptic stations reporting their wettest winter on record. Stations in the South and Midlands had $>350 \%$ their long-term average (LTA) precipitation (Met Éireann 2016a, 2016b). Nearly 50\% of river gauges operated by the Office of Public Works (OPW) reported their highest-ever river heights (National Directorate for Fire and Emergency Management, 2016). The heavy rains also brought extensive pluvial floods to the saturated ground beyond traditional floodplains. During Storm Desmond, the European Space Agency (ESA) Copernicus Emergency Management Service (Copernicus EMS) began monitoring flood development at several at-risk towns to provide highresolution spatial data to assist in emergency response. Rural parts of the Midlands and Western region, areas not routinely monitored by Copernicus EMS, were already flooded before Storm Desmond and would continue to be for several weeks.
Efficient monitoring of flood events is fundamental to minimising the impact on life and property. Satellite remote sensing, due to its wide field of view and continuous coverage, is widely used in flood mapping and monitoring. The Sentinel 1 mission is ESA's most recent synthetic aperture C-band radio detection and ranging (RADAR) (abbreviated as SAR) satellite with flood mapping capability (Malenovský et al., 2012; Amitrano et al., 2014), continuing the work of the earlier European Remote Sensing (ERS) and Environmental Satellite (ENVISAT) missions. Now fully operational, the Sentinel 1 mission deploys two polarorbiting satellites that can map surface water and flood water at $10 \mathrm{~m}$ spatial resolution every $6 \mathrm{~d}$. Several additional SAR satellite missions (e.g. ALOS-2, RADARSAT-2 and TerraSAR-X) also provide flood mapping capability (Arnesen et al., 2013; Bolanos et al., 2016). These and other RADAR missions contribute information to Copernicus EMS projects globally. In addition to flood delineation, SAR has been used elsewhere in surface hydrology to estimate surface soil moisture (Moran et al., 2004), to monitor river stage (Schumann et al., 2009) and to map preferential hydrological pathways (Manfreda et al., 2011). The use of optical and microwave satellite systems to map 
flooding and monitor recovery is well established (Rango and Solomonson, 1974; Profeti and Maclntosh, 1997; Joyce et al., 2009, Twele et al., 2016). Optical sensors (e.g. Sentinel 2, Landsat 8) map surface water based on the different reflectance characteristics for soil, vegetation and water in the visible, infrared spectrum. Reflectance-based mapping typically uses band combinations of near-infrared (NIR; 0.7 $\mathrm{mm}-1.4 \mathrm{~mm}$ ), shortwave infrared (SWIR; $1.4 \mathrm{~mm}-3 \mathrm{~mm}$ ) and green $(0.55 \mathrm{~mm}$ ) light to record changes in flood extent (Ouma and Tateishi 2006, Ji et al., 2011; Du et al., 2016). Thermal infrared images $(8 \mathrm{~mm}-13 \mathrm{~mm}$ ) may also be used (LeBlanc et al., 2014). The high thermal inertia (resistance to change in water temperature) and emissivity of water appear as areas of homogeneous surface temperatures when flooded. The potential of optical data for flood mapping is severely restricted by vegetation canopies, a dependence on solar energy and interference from clouds (Musa et al., 2015). Compositing daily images from high-temporal-resolution imagery (e.g. Moderate Resolution Imaging Spectroradiometer [MODIS] sensor aboard the Terra and Aqua satellites) can minimise cloud interference but at the loss of spatial resolution and mapping accuracy (Chen et al., 2013). Unmanned aerial vehicles (UAVs) have been applied to flood mapping over small areas using high-resolution imagery (Feng et al. 2015). Multispectral images can observe the effect of stress on crops (reduced photosynthesis production, stomata closure and decreased respiration; Carter and Miller, 1994), which can be used to infer prolonged soil waterlogging and to measure vegetation recovery. In broadband sensors, these stresses are typically characterised by reduced reflectance in the NIR region and increased reflection in red light. A normalised ratio of red and NIR bands, known as a normalised difference vegetation index (NDVI), exploits this relationship to identify healthy and senescent plants and is often used as a proxy for photosynthetic activity and plants biomass (Pettorelli, 2014). NDVI is a unitless index ranging from -1 to 1 ; healthy vegetation has high positive values, stressed vegetation has lower values, while bare soil and water have values around or less than zero, respectively. Several studies have shown a correlation between wet soil and NDVI values (Lozano-Garcia, 1991; Levine, 1994; Ciallela et al., 1997) and demonstrated crop response to inundation (Streyer et al., 2013; Džubáková et al., 2015) or other weatherbased natural disasters (Rodgers et al. 2009; Fu et al. 2014). Pantaleoni et al. (2007) used Landsat 5 Thematic Mapper NDVI images to quantify crop damage following severe flooding and the subsequent ponding of water on low-infiltration soils. A negative response was observed in difference images taken before and after submergence. NDVI differencing highlighted inter-annual disparity caused by flood damage (Michener and Houhoulis, 1997).

SAR is an active remote sensing technology that emits a RADAR pulse and measures returning backscatter. Unlike optical sensors, SAR can operate day or night, regardless of atmospheric conditions (Gibson 2000). Interpreting RADAR images is not as straightforward as for optical data. The strength of the returned signal, measured as a backscattering coefficient $\left(\mathrm{s}^{\circ}\right)$, is a function of sensor specification (wavelength, polarisation and incidence angle), as well as environmental factors at the surface (roughness, geometry and water content) (Campbell 2002). SAR flood mapping is usually undertaken at the $\mathrm{X}$-band ( $3 \mathrm{~cm}$ wavelength), C-band (5 $\mathrm{cm}$ wavelength) or L-band (23 cm wavelength). Longer wavelengths can penetrate deeper into thick vegetation canopy, although both X- and C-band SAR techniques have demonstrated capability in mapping wetlands and regions underlying a forest canopy (Lang and Kasischke, 2008). A surface is considered rough when it has dimensions comparable to the incident wavelength. Smooth water surfaces have low backscatter due to specular reflection and appear very dark, while rougher land surfaces reflect more energy and look brighter. Roughened water surfaces from strong winds, precipitation, high-flow velocity or partially flooded vegetation appear in different levels of grey and can be difficult to distinguish from land surfaces (Martinis et al., 2015). In certain instances, surface water below the canopy will increase backscatter relative to dry conditions due to increased signal reflectance (the double bounce effect) (Horritt et al., 2003).

SAR systems transmit and receive signals in single (horizontal $[H]$ or vertical $[V])$ or dual polarisations ( $\mathrm{H}$ and $\mathrm{V})$, along the geometric plane a RADAR pulse propagates. Four polarisation combinations are possible ( $\mathrm{HH}, \mathrm{HV}, \mathrm{VH}$ and $\mathrm{VV})$, and all can potentially be used for flood mapping. The HH (horizontal transmit, horizontal receive) polarisation often displays the highest contrast between water and land (Manjusree et al., 2012). Sentinel 1 can collect $\mathrm{HH}$ polarisation, but it is not systematically acquired over land surfaces (Sentinel 1 SAR User Guide, https://sentinel.esa.int/web/sentinel/user-guides/ sentinel-1-sar). VV polarisation (vertical transmit, vertical receive) data have generally been viewed as less capable than the HH data (Bourgeau-Chavez et al., 2001; Gstaiger et al., 2012), although VV polarisation has demonstrated superior ability in identifying partially submerged fields and features in certain circumstances (Manjusree et al., 2012). Using Sentinel 1 imagery, Twele et al. (2016) reported high classification accuracy ( $>94 \%$ ) using $\mathrm{VV}$ polarisation relative to that for $\mathrm{VH}$, the latter having a greater misclassification rate in agricultural lands. Clement et al. (2017) achieved similar accuracy (97\%) mapping winter floods in the UK in 2015-2016. Their study highlighted the utility of Sentinel 1 in identifying pluvial flooding at distances from water bodies, as well as a strong correlation between Sentinel 1 and Sentinel 2 flood maps.

Flood extents are generally derived from SAR images using a histogram-based, backscatter thresholding approach. This 
computationally fast and effective pixel-based method works by splitting the histogram into "water" and "non-water" classes based on a single backscatter value taken from the image histogram (Di Baldassarre et al., 2011; Sahoo et al., 1988). The threshold can be optimised using the Otsu algorithm or through careful manual adjustment (Otsu 1979). Its major limitation is that it provides a global threshold, which may not be suitable in all areas of the image. Other methods of segmentation include change detection (Brivio et al., 2002; Wang, 2002; Martinis et al., 2011), image segmentation and clustering (Horritt, 1999; Mason et al., 2012), or a combination of these techniques (Martinis et al., 2009; Matgen et al., 2011). Others have proposed artificial neural networks (Kussul et al., 2008) or support vector machines (Insom et al., 2015) for supervised classification of SAR images. Long et al. (2014) and Clement et al. (2017) have defined thresholds based on image differencing between wet and dry periods, where regions with the greatest negative change in backscatter were classified as inundated. Huang et al. (2017) have proposed a threshold based on terrain indices derived from coarse-resolution digital elevation models (DEMs), as a way of defining surface water and shadow effects.

Flood depth and volume can be estimated by combining RADAR imagery with DEMs to determine the elevation of the land-water interface (Puech and Raclot, 2002; Matgen et al., 2007). Water height extraction at coarse $(\sim 30 \mathrm{~m})$ spatial resolution is possible (LeFavour and Alsdorf, 2005; Kiel et al., 2006); however, such DEMs are generally associated with low vertical accuracy and are unsuited to terrain or hydrological modelling (Li and Wong, 2010). At coarse resolution, the loss of definition of fine-scale topographic information (e.g. river embankments, hedges and walls, ditches, etc.) through pixel aggregation can lead to overprediction of flood extents and depth (Sanders, 2007; Cook and Merwade, 2009). Highresolution elevation data from laser scanning (light detection and ranging [LIDAR]) and aerial photogrammetry can more accurately model topographical surfaces and improve estimates of flood extent and depth (Charlton et al., 2003; Coveney and Roberts, 2017).

In response to extensive flooding in winter 2015-2016, the goal of this pilot study was to investigate the feasibility of extending RADAR mapping coverage for the Republic of Ireland using Sentinel 1 backscatter data. The objectives of the study were as follows:

1. To create flood maps at regular intervals to monitor the development of flooding at a national scale, with a focus on rural areas;

2. To determine the worst-affected areas and identify areas of persistent flooding;

3. To estimate flood depth and volume;

4. To assess the accuracy of the produced map against ground truth, as well as in relation to RADAR (Copernicus
EMS) and optical (Sentinel 2) flood maps;

5. To observe post-flood recovery in vegetation canopy using Landsat $8 \mathrm{NDVI}$ images.

\section{Materials and methods}

\section{Satellite data}

A total of 33 RADAR images were created from Sentinel 1A backscatter data captured every $12 \mathrm{~d}$ from 19 November 2016 until 23 February 2016, and intermittingly after that, on 30 March and 11 April. Data were downloaded from ESA's Sentinel Scientific Data Hub (SciHub; https://scihub.copernicus.eu). The selected imagery provided almost national coverage. Two narrow strips of land along the eastern and western coasts, which lay outside the chosen image swaths, were omitted from the study to reduce processing time. RADAR scenes are available for these areas. The area of land in the omitted swaths is relatively small and predominantly coastal or mountainous. They were considered unlikely to contain regions of flooding pertinent to this study. Data specifications for the Sentinel missions are provided in Table 1. To allow a comparison with currently available RADAR flood maps, Copernicus EMS flood maps (EMS rapid mapping [EMSR]; EMSR149) for an area surrounding Athlone, Westmeath (13 December 2015) were downloaded from the Copernicus EMS website (http://emergency.copernicus.eu/mapping).

Multispectral imagery (21 December 2015) from Sentinel 2A was also downloaded from SciHub to allow a comparison with Sentinel 1 flood maps. These were downloaded as topof-atmosphere (TOA) products (Level 1C) and converted to surface reflectance using a dark-object subtraction algorithm (Chavez, 1996) in the Semi-Automatic Classification plugin (v.5.2.2) in the geographic information system software QGIS (v.14.2). Satellite images require several stages of processing to geometrically and radiometrically correct raw data. TOA data have higher reflectance values as the dataset includes scattered light reflecting off atmospheric particles (dust, molecules and water vapour), as well as cloud and cloud shadow on the surface. These can be a source of error in earth observation studies and need to be eliminated or minimised to provide actual surface reflectance values.

To demonstrate the effect of persistent flooding on pasture yields the following spring, a mosaic of $18 \mathrm{NDVI}$ images from April and May 2016 covering the Border, Midland and Western regions were compiled from United States Geological Survey (USGS) Landsat 8 scenes. Mosaics were created for flood (spring 2016) and non-flood (spring 2015) years. NDVI images were created using the established equation (NIR - red)/(NIR + red) (Tucker 1979). Landsat was preferred to Sentinel 2 because of its extensive image archive, which 
Table 1. Data specifications for the Sentinel satellites

\begin{tabular}{|c|c|c|}
\hline & Sentinel 1A & Sentinel 2A \\
\hline Frequency/wavelength & C-band $(5.4 \mathrm{GHz})$ & $0.443 \mathrm{~mm}-2.150 \mathrm{~mm}$ (VIS-SWIR) \\
\hline Orbit & $693 \mathrm{~km}$ (sun-synchronous) & 786 km (sun-synchronous) \\
\hline Interval & $12 \mathrm{~d}$ & $10 \mathrm{~d}$ \\
\hline Acquisition dates & $\begin{array}{c}19 \text { Nov. } 2015 \\
\text { 1, } 13,25 \text { Dec. } 2015 \\
6,18,30 \text { Jan. } 2016 \\
\text { 11, } 23 \text { Feb. } 2016 \\
30 \text { Mar. } 2016 \\
\text { 11 Apr. } 2016\end{array}$ & 21 Dec. 2015 \\
\hline Mode & Interferometric wide swath & Multispectral imager \\
\hline Swath width & $250 \mathrm{~km}$ & $290 \mathrm{~km}$ \\
\hline Product & Level-1 ground range detection & Level-1C top of atmosphere reflectance \\
\hline Spatial resolution & $10 \mathrm{~m}$ & $10 \mathrm{~m}, 20 \mathrm{~m}$ \\
\hline Polarisation & $\mathrm{VV}+\mathrm{VH}$ & - \\
\hline$\%$ cloud cover & - & $3 \%$ \\
\hline
\end{tabular}

covered the duration of the study period. TOA images were downloaded from the USGS website (Earth Explorer; https:/earthexplorer.usgs.gov). Masking of cloud and cloud shadow was accomplished using the F-mask algorithm (Zhu et al., 2015) and converted to surface reflectance using the Landsat Ecosystem Disturbance Adaptive Processing System (LEDAPS) algorithm (Schmidt et al., 2013). NDVI values, based on mean pixel values within a $25 \mathrm{~m}$ radius, were extracted at $\sim 4,000$ randomly selected locations.

Existing water bodies (rivers and lakes) were extracted from Ordnance Survey Ireland (OSI) vector data and used to mask the normal extent of surface water. This mask included the locations of 128 turloughs, seasonally flooded wetlands in karst regions, which were obtained from the Environmental Protection Agency (EPA) (Johnston, Turlough Database). Hydrograph data for river gauge stations were obtained from the OPW. Daily average river heights were extracted from 10 stations within the River Shannon catchment. Daily precipitation data were downloaded from the meteorological service for 391 stations distributed across the country. Daily values were aggregated to give mean rainfall values. Land cover data were extracted from the 25 ha Coordination of Information on the Environment (CORINE) database, available at the EPA. Soil and subsoil information was available through the Teagasc Soils and Subsoils database (Fealy et al., 2009). This subsoil map had a nominal working scale of 1:50,000 and included a classification of soils into poor and well drained.

A $20 \mathrm{~m}$ spatial resolution DEM ( $\pm 2.5 \mathrm{~m}$ vertical error) from the OSI was used to estimate flood depth and volume. DEM resolution and accuracy have a significant impact on water surface elevations and flood extent (Darnell et al., 2008; Fisher and Tate, 2006). The averaging of elevation values within coarse footprints can subdue local elevation maxima and topographic depressions, which can overpredict flood area (Brandt 2005; Zandbergen 2006). Monte Carlo simulations have been widely applied to DEM to quantify error propagation from positional uncertainty (Heuvelink et al., 1989; Wechsler and Kroll, 2006; Zandbergen, 2011; Leon et al., 2014). They have been used in flood and surface hydrological modelling (Wu et al., 2008; Domeneghetti et al., 2013; Bodoque et al., 2016). A Monte Carlo simulation of 500 perturbed DEMs was created, which included a random error term drawn from the original root mean square error (RMSE). These were produced in geographic information system software ArcGIS using the methodology proposed by Zandbergen (2011). Errors were normally distributed and spatially autocorrelated based on a five-cell neighbourhood (50 m). The modified DEM was resampled to $10 \mathrm{~m}$ (ArcGIS) using bilinear interpolation to match the spatial resolution of Sentinel 1. Maximum elevation heights beneath individual flood regions were extracted from the modified DEMs using a zonal statistics algorithm (ArcGIS), which calculates summary statistics on raster values based on zones within another dataset. The maximum DEM elevation value below each zone was assumed to represent the maximum height reached by the flood waters. The difference between the DEM elevation and this maximum value permitted a pixel-by-pixel estimate of flood depth (in metres), which was converted to volume by multiplying by the pixel area.

\section{Flood mapping procedure}

Map creation followed the recommended practice published by the United Nations Space-based Information for Disaster Management and Emergency Response (UNSPIDER) portal (UN-SPIDER Knowledge Portal 2016). The image processing workflow was executed through ESA's 
Sentinel Application Platform, SNAP (v.4.0), following a step-by-step procedure of calibration, filtering, masking and rectification. The subsequent analysis used ArcGIS (v.10.2.2), QGIS and R statistical software (v.3.2.3). The map (Figure 1) is available as a download (raster format) from the Teagasc data repository T-stór (www.t-stor. teagasc.ie) and through the ArcGIS Online portal (www. esri.com). Displayed projection coordinates are Irish Transverse Mercator (European Petroleum Survey Group [EPSG] code 2157).

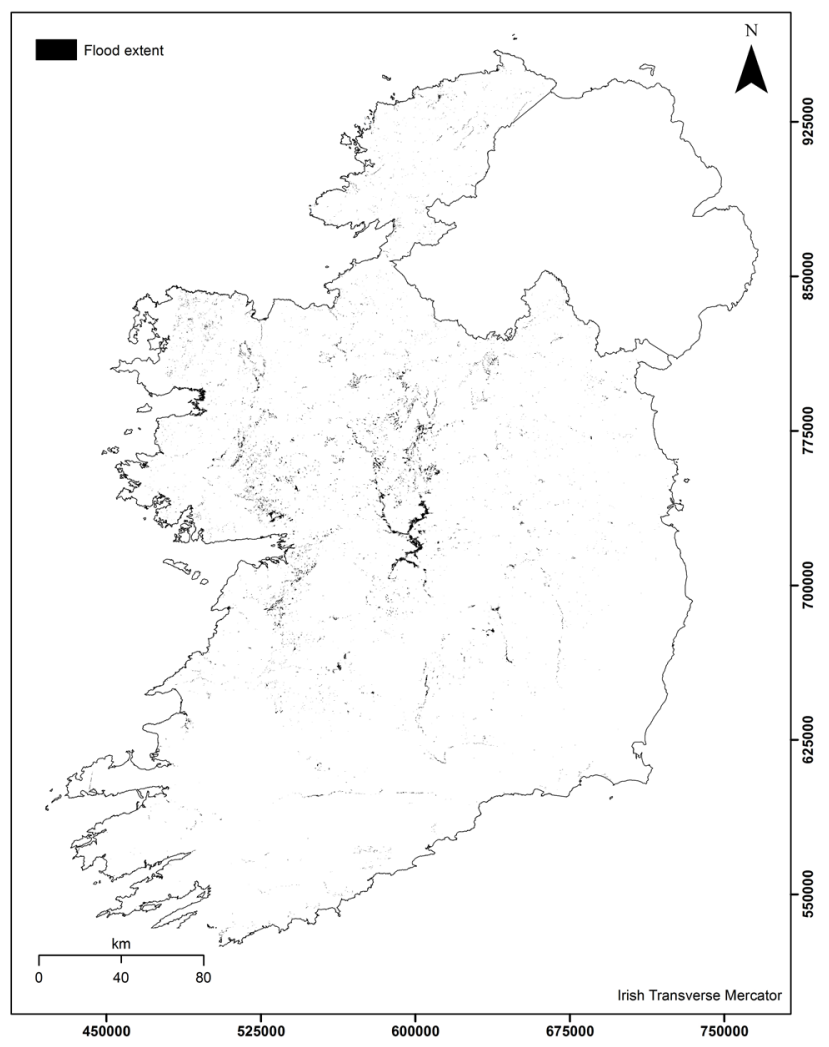

Figure 1. Estimated extent of flooding in the winter of 2015-2016 (areas $>0.01$ ha and flooded on $>1$ occasion).

The initial step created a calibrated backscatter image (10 $\mathrm{m} \times 10 \mathrm{~m}$ pixel) in decibels $(\mathrm{dB})$ in $\mathrm{VV}$ polarisation. These images contain inherent speckle, which is the random granular noise in SAR images caused by heterogeneous scattering surfaces within a pixel. Speckle changes scene backscatter values, which can hinder accurate image segmentation and classification (Mansourpour et al., 2006). It was removed using a Lee-Sigma filter, which assumes that speckle follows a Gaussian distribution and replaces central pixels within a $7 \times 7$ pixel moving window with the average of all values that fall within 2 s.d. (Lee, 1983). A backscatter value for flood water was manually determined for each of the 33 scenes through visual inspection of the image histograms. Each histogram typically displayed a bimodal or multimodal distribution. Low backscatter values corresponded to flat water (including noise) and high values corresponded to nonwater classes, allowing a binary segmentation on the images into water or non-water pixels. A mean threshold was defined for each image from backscatter values recorded at known surface water locations. Images were then transformed from internal sensor geometry to a projected coordinate reference system (World Geodetic System [WGS] 1984) using inherent ground control references and National Aeronautics and Space Administration (NASA)'s Shuttle RADAR Topography Mission (SRTM) Global 3 arc-second DEM. Individual scene masks were mosaicked into one image for each acquisition date in ArcGIS. To reduce potential misclassification arising from erroneous threshold definition and uncorrected speckle effect, isolated single-pixel flooded areas ( $0.01 \mathrm{ha})$ and pixels classified as inundated on just one occasion were excluded from analysis $(24,166$ ha in total).

\section{Noise removal}

Thresholding invariably misclassifies pixels at the class boundary due to the binary nature of the thresholding process. Regardless of the method used, thresholding uses a single point to separate pixels. This creates noise, which must be reduced. Noise in this study is defined as low backscatter values not associated with flooding. The principal sources of noise included topographic shadow (where slopes in the opposite direction of image acquisition are observed with very low or zero backscatter), estuaries and beaches (which appeared as water or not, depending on the tidal regime); flat constructed surfaces (e.g. car parks, extensive flat roofs, airport runways); and anomalies created during processing (banding along the swath's edges and merged boundaries). Most scene- and sensorrelated noise was masked using a summer RADAR image by identifying normally occurring low-backscatter regions. A slope mask filtered out surface gradients greater than $5^{\circ}$, which could cause shadowing. Masking turloughs entirely was challenging and, hence, these remained a source of unknown error within the final map. These are low-lying areas of limestone geology, which become flooded in wet weather through the rising of groundwater. Defining a fixed boundary for these wetlands is difficult as water levels are dynamic. The weather on the date of acquisition is a further source of noise. Surface waters roughened by high-velocity flow, rainfall and speedy winds during acquisition may not appear smooth with C-band SAR. 


\section{Results}

\section{Extent}

The final flooded area (Figure 1) on each acquisition was calculated as the summed area of pixels remaining after noise removal. The calculated area was 24,356 ha, which is greater than the combined surface area of Loughs Ree and Derg $(22,300 \mathrm{ha})$, two lakes on the River Shannon. To account for the $7 \mathrm{~m}$ positional inaccuracy ( $<1$ pixel) in Sentinel 1 Interferometric Wide Swath registration (Bourbigot et al., 2016), flooded boundaries were expanded and trimmed by 1 pixel width $(10 \mathrm{~m})$ and the area recalculated. The possible flood extent was determined to be 16,155 ha-32,957 ha. An estimate for mean extents on each acquisition date are presented in Table 2.

Table 2. National flood extent on each acquisition date

\begin{tabular}{lc}
\hline Acquisition date & Area (ha) \\
\hline 19 November 2015 & 10,380 \\
1 December 2015 & 10,780 \\
13 December 2015 & 19,950 \\
25 December 2015 & 17,720 \\
6 January 2016 & 9,920 \\
18 January 2016 & 9,575 \\
30 January 2016 & 15,880 \\
11 February 2016 & 19,360 \\
23 February 2016 & 2,620 \\
30 March 2016 & 2,500 \\
11 April 2016 & 7,630 \\
\hline
\end{tabular}

Approximately 3,000 ha were flooded on eight or more dates, while 70 ha were flooded for the entire period of the study (Table 3). Distinct flooded regions ranged from 0.02 ha to a maximum of 846 ha. The worst-affected counties bordered the River Shannon, with more than half the flooded area $(\sim 12,500$ ha) occurring in counties Galway, Mayo and Roscommon. These were also the counties that received substantial humanitarian assistance payments in the period during and after the floods (National Directorate for Fire and Emergency Management, 2016). The peak flood event occurred on 13 December, with a flood of 19,950 ha. A second flood on 11 February reached 19,360 ha. Persistence of flood waters over the period is demonstrated in Figure 2 for an area around Shannonbridge, Offaly. Located at the confluence of the River Shannon with the River Suck and River Brosna, flood levels in this area remained largely unchanged from November 2015 until February 2016. In Figure 3, the variability in flood duration is illustrated, reflecting changes in flood height between flights. Pixels are coloured by the number of times they were classified as flooded. Most of the region depicted in this figure was inundated for a period between six and nine acquisition dates. Smaller areas were flooded in this figure for the entire period of the study.

Table 3. Number of times a pixel was classified as flooded, indicating the extent of persistent flooding

\begin{tabular}{lc}
\hline Number of times flooded & Area (ha) \\
\hline 1 & 22,160 \\
2 & 6,840 \\
3 & 4,470 \\
4 & 3,350 \\
5 & 2,750 \\
6 & 2,520 \\
7 & 2,035 \\
8 & 1,340 \\
9 & 720 \\
10 & 260 \\
11 & 70 \\
\hline
\end{tabular}

Flood extent showed a strong, positive correlation with total precipitation depth in the days preceding the flood event. Ordinary least squares linear regression was calculated to predict the flood extent based on the total rainfall depth over several days. A significant regression was found in several cases (Table 4). The model with the highest explanatory power was that for $5 \mathrm{~d}$ rainfall $(P=0.008)$, with an adjusted $R^{2}$ of 0.51 . The model with the least explanatory power was for

Table 4. Results of linear regression for the effect of rainfall depth on flood extent

\begin{tabular}{lccc}
\hline $\begin{array}{l}\text { Number of } \\
\text { days of rainfall }\end{array}$ & F-value, d.f.(1,9) & $P$-value & Adjusted $R \mathbf{2}$ \\
\hline 1 & 1.76 & 0.22 & 0.07 \\
2 & 8.34 & 0.02 & 0.42 \\
3 & 10.13 & 0.01 & 0.47 \\
4 & 2.79 & 0.13 & 0.15 \\
5 & 11.4 & 0.008 & 0.51 \\
6 & 3.6 & 0.08 & 0.22 \\
7 & 7.51 & 0.03 & 0.38 \\
8 & 5.17 & 0.05 & 0.29 \\
9 & 5.69 & 0.04 & 0.32 \\
10 & 6.26 & 0.03 & 0.34 \\
11 & 5.91 & 0.04 & 0.33 \\
12 & 5.76 & 0.04 & 0.32 \\
13 & 6.17 & 0.03 & 0.34 \\
14 & 6.24 & 0.03 & 0.34 \\
15 & 7.64 & 0.02 & 0.40 \\
16 & 8.83 & 0.02 & 0.44 \\
17 & 7.434 & 0.02 & 0.39 \\
18 & 7.28 & 0.02 & 0.39. \\
19 & 6.14 & 0.04 & 0.34 \\
20 & 6.70 & 0.03 & 0.36 \\
\hline
\end{tabular}



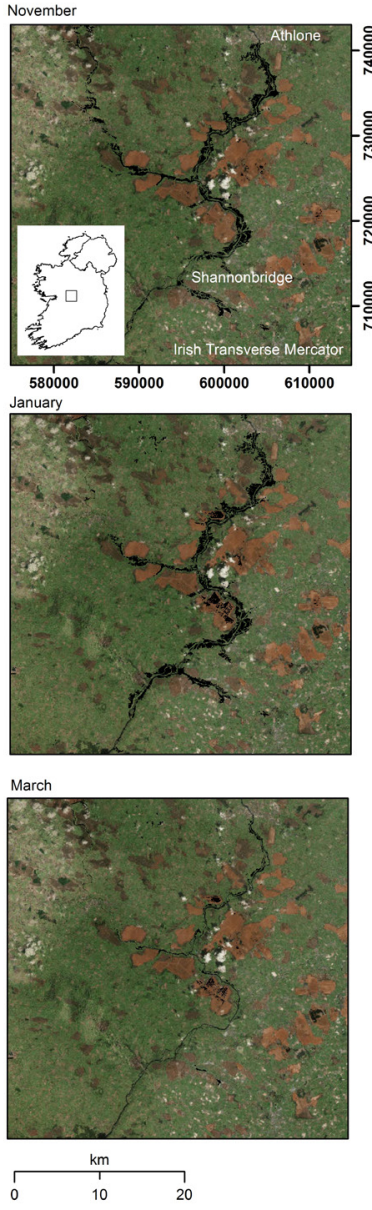
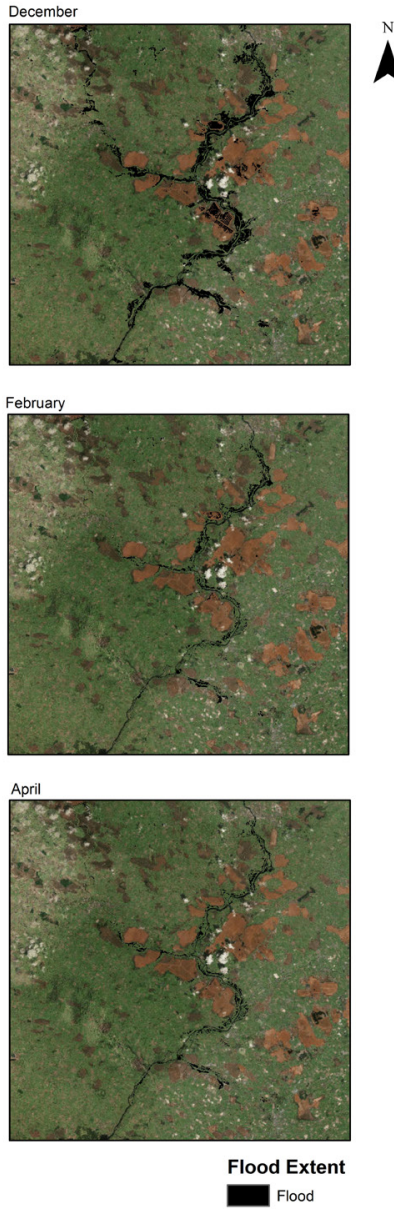

Figure 2. Flood extent at Shannonbridge, Offaly (November 2015-April 2016).

$1 \mathrm{~d}$ rainfall $(P=0.217)$, with an adjusted $R^{2}$ of 0.07 . Results from models with rainfall for $4 \mathrm{~d}$ and $6 \mathrm{~d}(P=0.13$ and $P=$ 0.22 , respectively). Beyond $6 \mathrm{~d}$, significant effects were found at each interval; however, the explanatory power of these models was weaker compared with the model for $5 \mathrm{~d}$ rainfall (Figure 4).

The majority of affected soils were alluvial or lacustrine $(8,100$ ha, or $33 \%$ of the flooded area), cut-over peat $(7,000$ ha, $28 \%)$ or poorly drained soils $(1,500$ ha, $6 \%)$. However, approximately 3,000 ha $(13 \%)$ was previously classified as "well drained" (mainly brown earths and brown podzols; Fealy et al. 2009). A large proportion of flooded land ( $61 \%)$ was agricultural, of which $\sim 50 \%$ was pasture, with an additional $11 \%$ in areas principally dominated by agriculture but with significant natural vegetation also. The area of arable and forested land affected was negligible (each <1\%). Peats and inland marshes made up $23 \%$ of the total. Urban areas (including sports facilities and industrial/transport-related land cover) constituted $<2 \%$ of inundated land mapped by Sentinel 1 . The remaining $\sim 13 \%$ was made up of several categories of land cover (e.g. marine and inland waterways, beaches, quarries etc.).

\section{Depth/volume}

Using mean flood heights derived from the Monte Carlo simulations, flood volumes were estimated at 528,863,333 $\mathrm{m}^{3}$ (95\% confidence interval: 482,078,000 $\mathrm{m}^{3}, 575,648,500 \mathrm{~m}^{3}$ ). In comparison, Lough Ree, the second largest lake on the River Shannon, has an estimated volume of $\sim 650,000,000 \mathrm{~m}^{3}$. To further determine the error distribution of the estimated flood depth, a further 2,500 Monte Carlo simulations were run on a subset region using the "spup" package (v.0.1-1) in $\mathrm{R}$. Confidence intervals around the estimated mean values decreased with increasing number of simulations (Figure 5). There was no significant difference in depth values between DEM based on 500 simulations and those created with 1,000 or 2,500 simulations $(P=0.143$ and $P=0.12$, respectively). Flood 


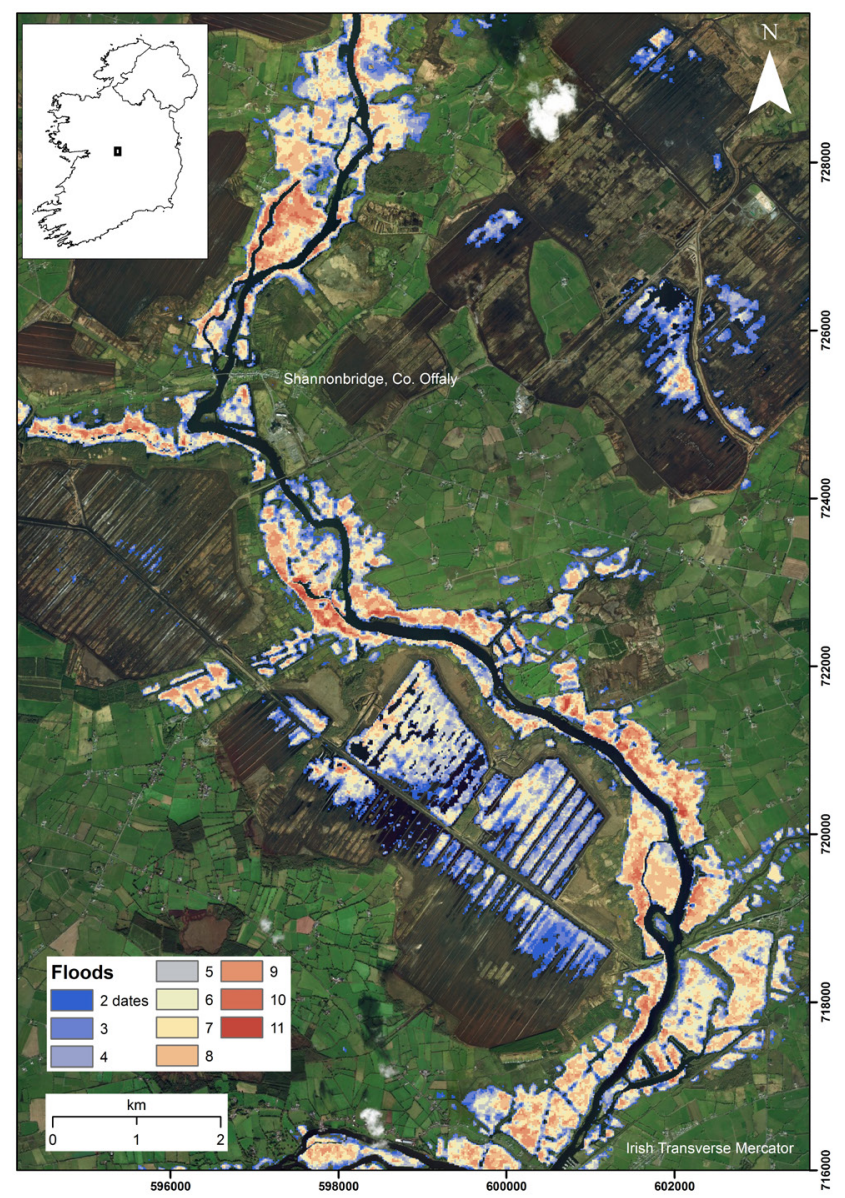

Figure 3. Persistence of flooding at Shannonbridge, Offaly. Each colour represents the number of times a pixel was classified as flooded.

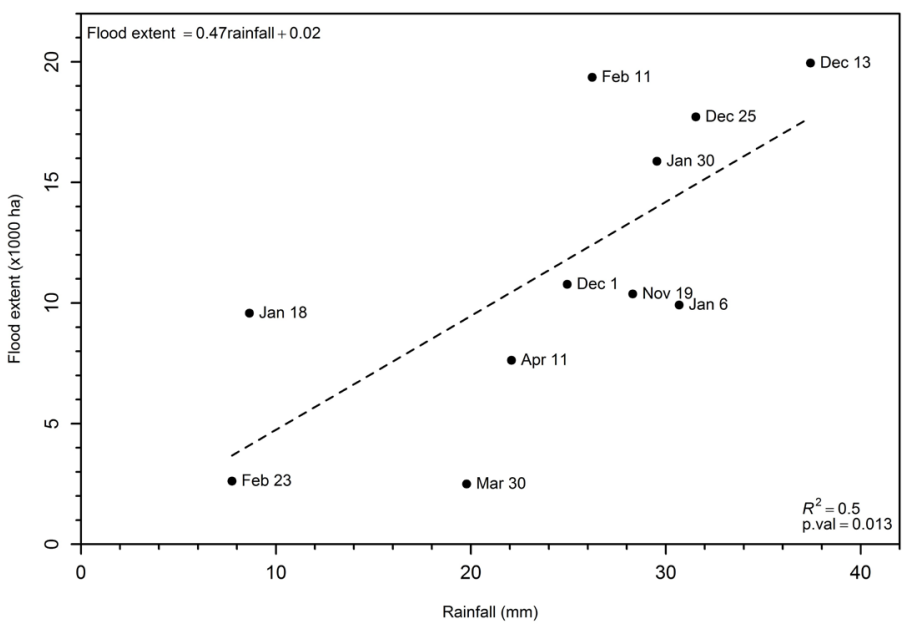

Figure 4. Flood extent vs. rainfall in the previous $5 \mathrm{~d}$. 

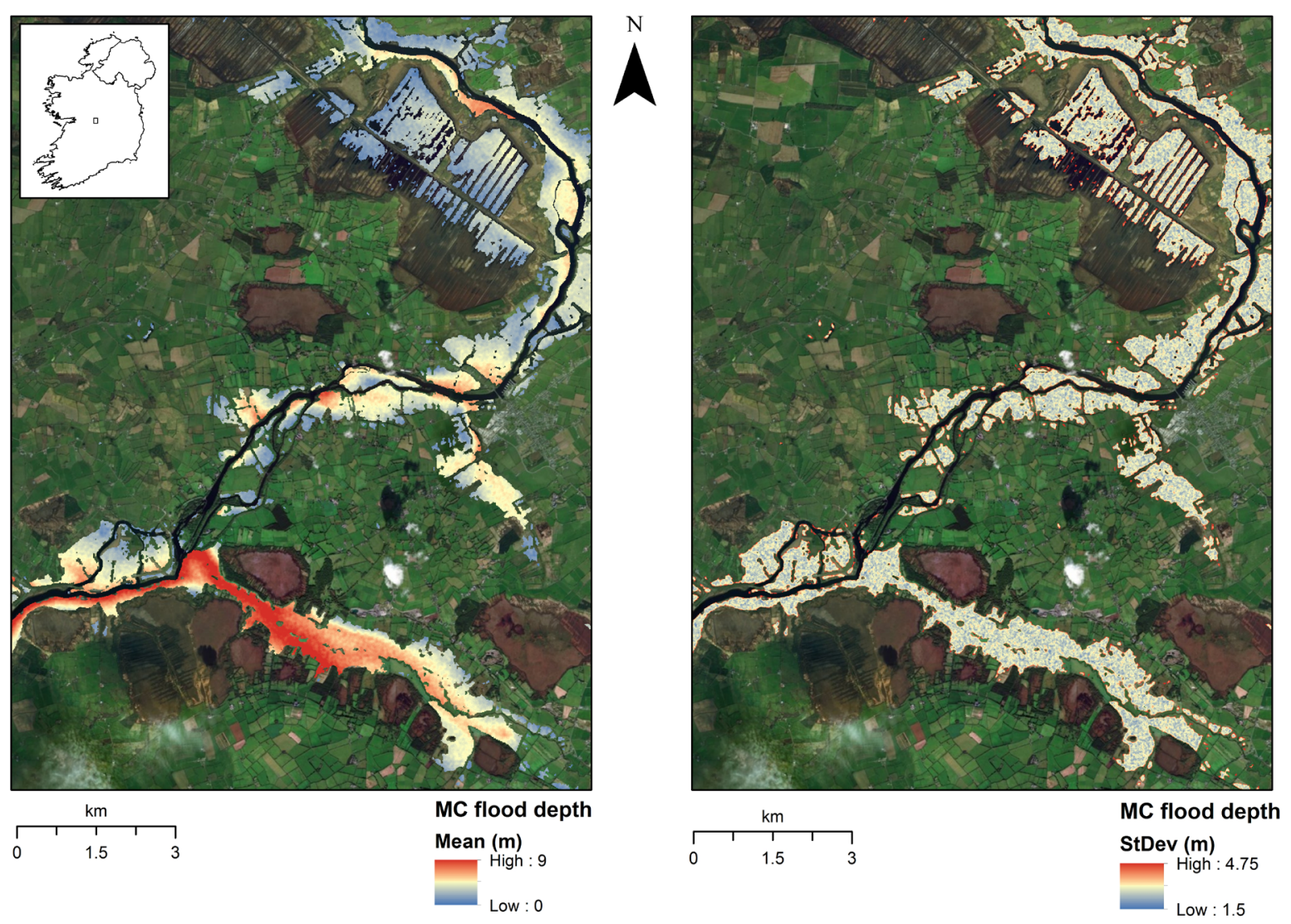

Figure 5. Example of variable mean and $95 \%$ confidence intervals for flood depth at a sample location with increased Monte Carlo simulations.

depths generated using this modified DEM are illustrated in Figure 6. As expected, areas closest to river channels are deeper, and depth decreases with Euclidean distance from the channel. Standard deviations for each pixel illustrate the error range present within a small and topographically homogeneous area. Histograms for four randomly selected points further illustrate the error distribution for depths at these grid cells. Mean flood depths vary by location. However, the s.d. across the subset region is approximately $1.95 \mathrm{~m}$.

\section{Damage to farms}

Teagasc farm advisors nationwide conveyed damage reports from affected farmers, including lost bales of hay or silage, drowned animals and flooded buildings and yards (Teagasc, personal communication). A greater proportion of the buildings flooded on $>1$ occasion were agricultural buildings. Intersecting the map with building location data from the OSI, 13 of 24 buildings (54\%) identified as within the national flood extent could be classified as agricultural in high-resolution aerial imagery. When areas flooded only once were included, the number of flooded agricultural buildings was 35 of 125 $(28 \%)$. The remaining structures were predominantly rural domestic properties (many in coastal locations), riverside and lakeside buildings (sheds, boat houses) and structures within sports facilities and industrial/transport sites.

The effect on crops may not have been immediately evident. Mean NDVI values for pastures within the flooded area the following spring 2016 was 0.70 (s.d.: 0.18). By comparison, in the same period, mean NDVI values for non-flooded grassland on poorly drained and well-drained soils were 0.78 (s.d.: 0.11 ) and 0.80 (s.d.: 0.12), respectively. A non-parametric KruskalWallis rank sum test carried out using the "stats" (v.3.4.1), and "dunn.test" packages (v.1.3.4) in R found that flooding had a significant effect on grassland NDVI values the following spring $(P$-value $<0.001)$. Pairwise multiple comparisons showed no evidence for different median NDVI values during the first eight events. There were significant differences in NDVI values for flood events numbering between eight and 


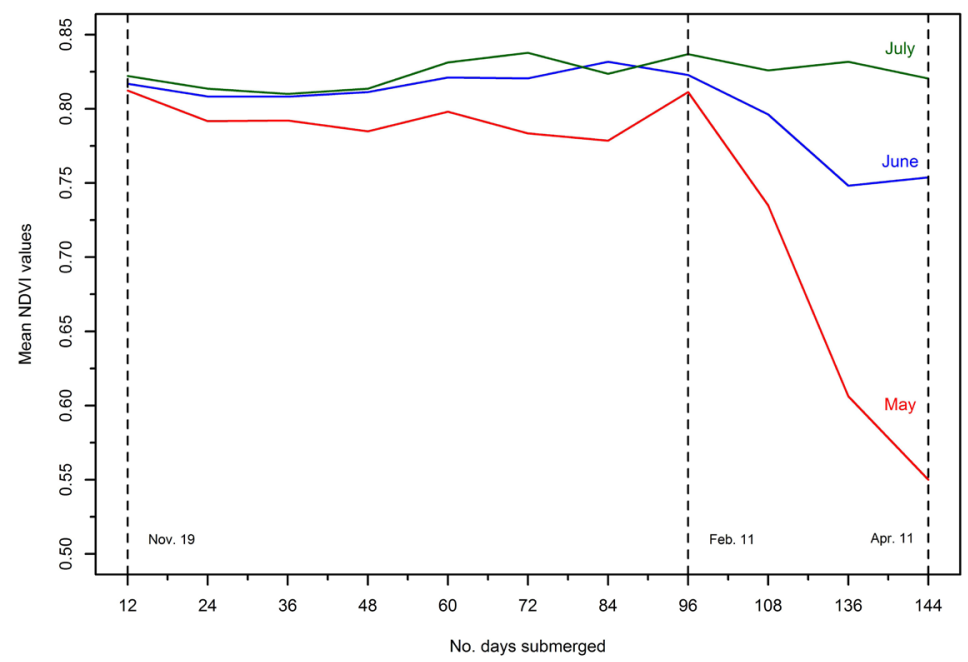

Figure 6. Mean and s.d. of estimated flood depths at Athlone, Westmeath. Depth uncertainty is shown as the error distribution histograms at four randomly selected points.

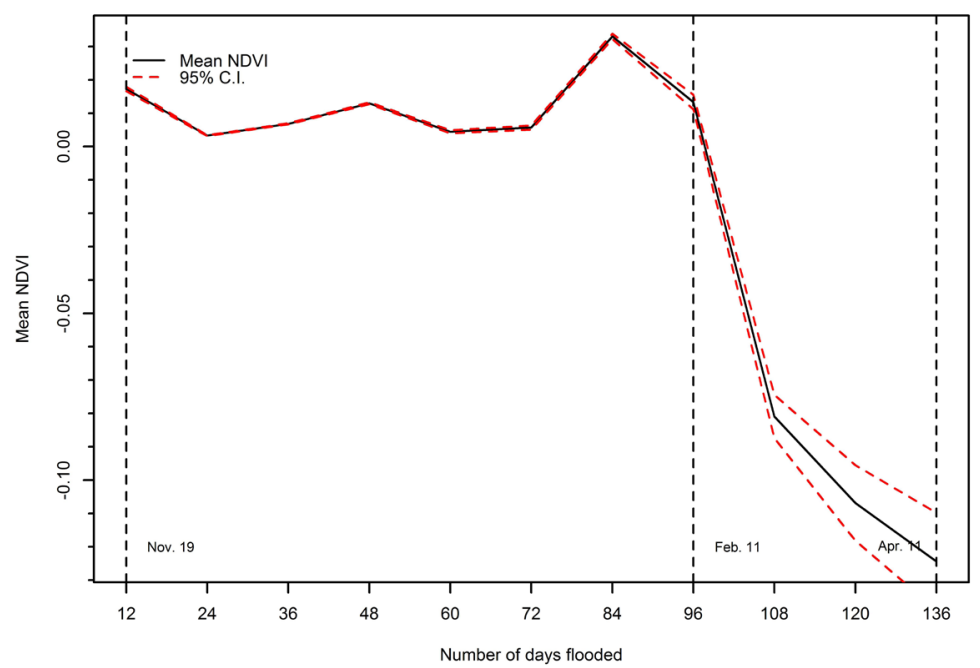

Figure 7. Mean NDVI values for flooded pasture (April/May 2016) as a function of flood duration. Values are based on mean NDVI values within $25 \mathrm{~m}$ of sample locations $(n=4,000)$.

nine $(P$-value $<0.001)$ and between nine and $10(P$-value $<0.001$ ) (Figure 7). An inter-annual comparison between NDVI values in 2016 and 2015 showed a similar trend with no significant differences between the years until after eight flood events (Figure 8). Spring 2015 weather conditions were typical, with air temperatures at or marginally lower than LTAs. Growing conditions may have been depressed in certain areas as a result of the above-average rainfall, which was heavy in places (Met Éireann, 2015).

\section{Validation}

The map was validated against three independent sources:

1. Reports of flooded fields from individual farmers;

2. Flood map created from Sentinel 2 optical data of Athlone, Westmeath;

3. Copernicus EMS flood map (EMSR149) of Athlone, Westmeath.

Reports of flooded farms directed to Teagasc advisors provided a direct means of validating the map. A database 


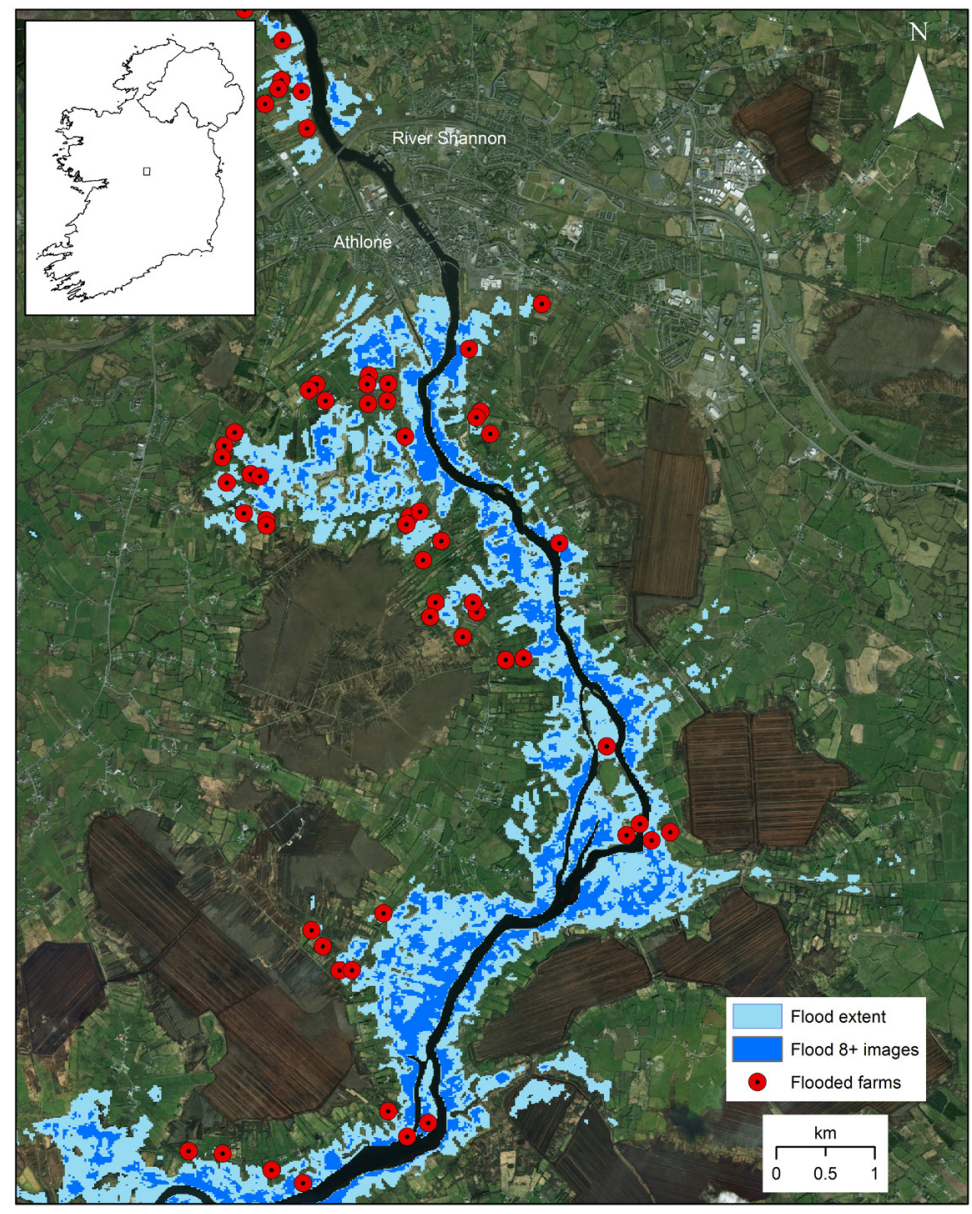

Figure 8. Difference in NDVI values between spring 2015 and spring 2016 for flooded pasture. Values are based on mean NDVI values within $25 \mathrm{~m}$ of sample locations $(n=5,422)$.

of 57 farms that reported flood damage was overlaid with the estimated extents. Accordingly, 49 farms intersected the flood boundary, an $86 \%$ agreement between field and satellite data. There was no way of identifying Type 1 errors (false positives) among these reports, as only flooded properties were listed. The mean inundated area on these farms was $\sim 3$ ha, with the area maximum flooded for any one farm reaching 176 ha. Most flooded farms were immediately adjacent to the River Shannon. Moreover, 55 flooded fields were $>500 \mathrm{~m}$ from a water body, emphasising the extensive reach of flood waters and the role of pluvial flooding in the overall flood magnitude. Flooded farms in the Shannonbridge/Athlone areas are illustrated in Figure 9.

Clear skies across the Midlands on the morning of 21 December (3\% cloud cover) allowed Sentinel 2 to capture surface reflectance. This facilitated a comparison of optical and microwave methods of map creation at the same spatial resolution (10 m). A normalised difference of green and SWIR bands (commonly called a normalised difference water index, NDWI) (McFeeters, 1996) was used to map the floods for a region of interest south of Athlone, Westmeath. The green shaded area in Figure 10 shows the inundated area seen by Sentinel 2 on 21 December, and the blue shaded area is the flood extent obtained from Sentinel 1 on 25 December. There was a $58 \%$ overlap between these maps within this region of interest. The disparity is probably due to a 4-d separation in overpasses, as well as concomitant changes in water levels over this period. It is also worth noting that during the Sentinel 1 overpass, weather stations recorded $17 \mathrm{~mm}$ of rain that day (more than the LTA for December), with a wind speed of approximately $4 \mathrm{~m} / \mathrm{s}$ gusting to $11 \mathrm{~m} / \mathrm{s}$. These conditions could have sufficiently roughened the water surface to increase backscatter above the defined threshold values.

The final validation of the flood extent was a comparison with the Copernicus EMS map. Maps from 13 December were compared with Sentinel 1 maps from 25 December using an 


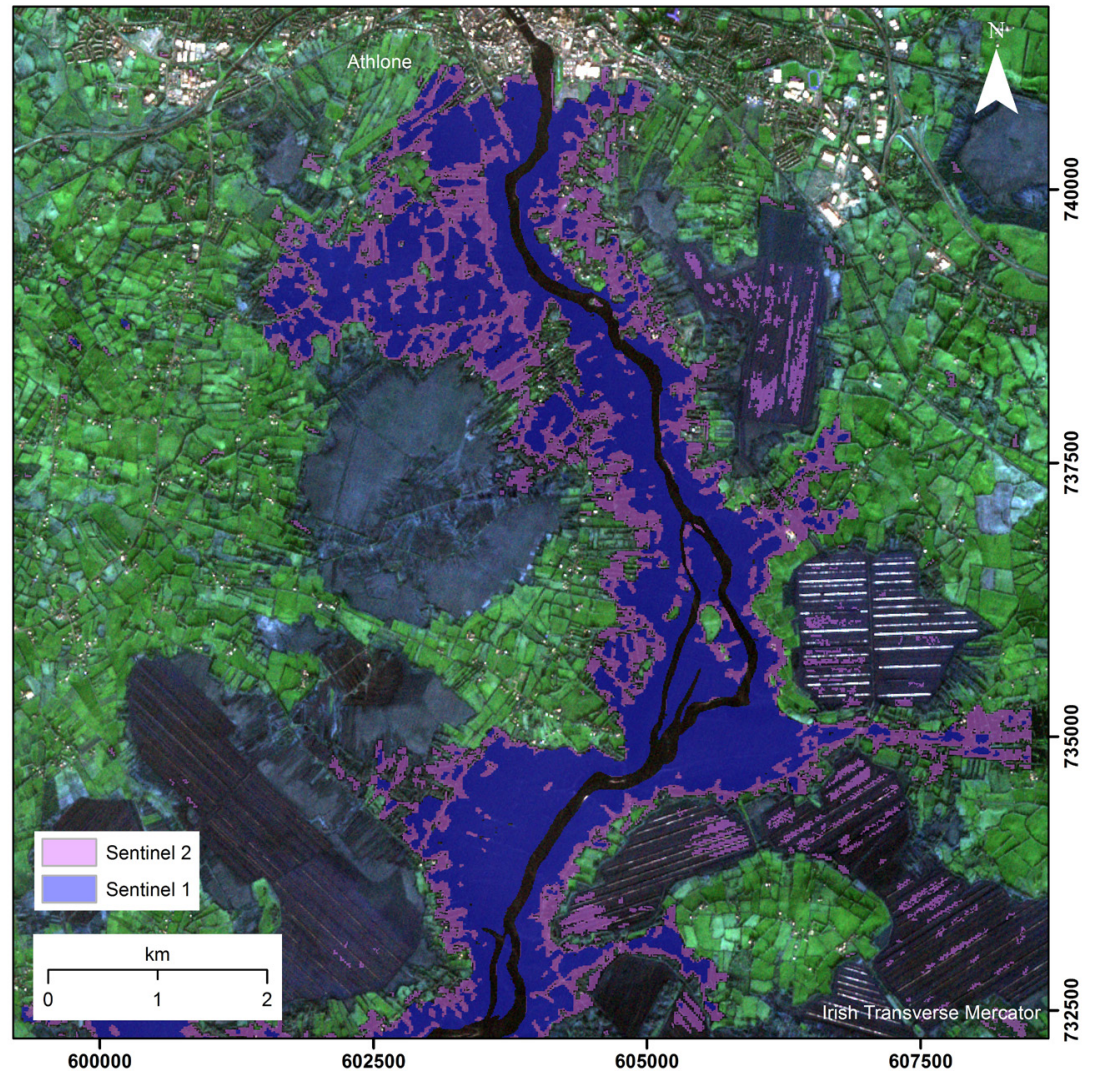

Figure 9. Farms reporting floods in the environs of Athlone, Westmeath. Areas flooded on $>8$ dates are coloured dark blue.

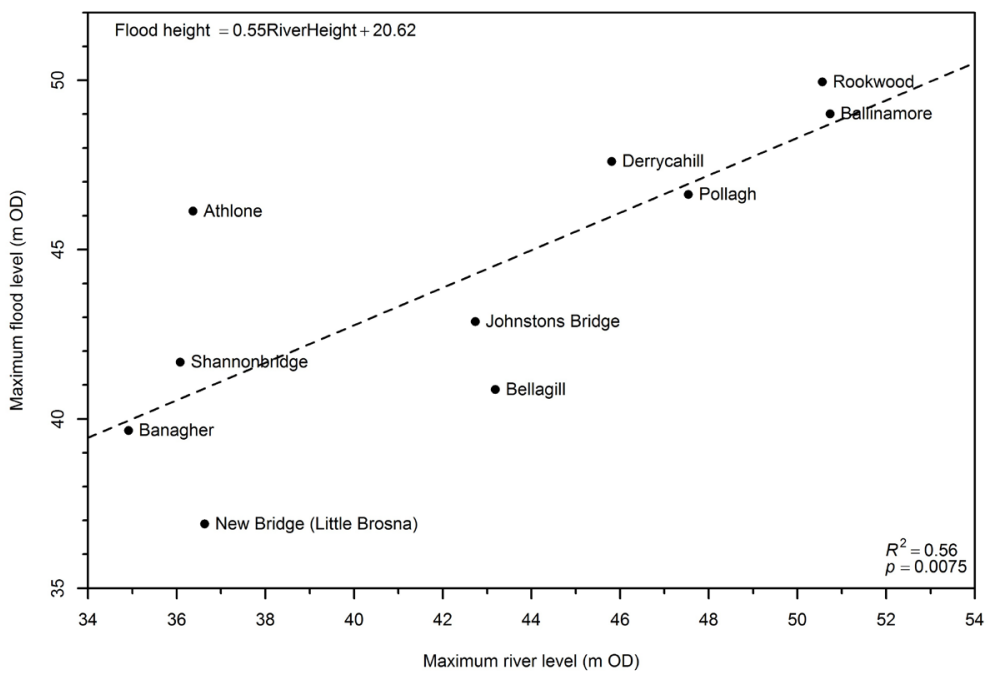

Figure 10. Comparison of flood maps from Sentinel 1 (25th December) and Sentinel 2 (21st December) imagery. Base map is an ESA Sentinel 2 red, green and blue (RGB) image at $10 \mathrm{~m}$ resolution. 
error matrix (Congalton and Green, 2008). As Copernicus draws data from a number of sensors and polarisations, it was assumed to have greater accuracy. The Sentinel map showed good agreement to Copernicus data, with $79.5 \%$ of pixels matching (Table 5). Local meteorological conditions on 13 December were mild $(3 \mathrm{~mm}$ rainfall, speed $4 \mathrm{~m} / \mathrm{s}$ gusting to $10 \mathrm{~m} / \mathrm{s}$ ), so weather conditions are unlikely to be responsible for the difference in classification. Low user accuracy of the Sentinel 1 data for flooded areas (66\%) probably reflected the reduced ability of the $\mathrm{C}$-band sensor to resolve flooding in the presence of canopy vegetation. It may also reflect actual differences in flood height on different acquisition dates. Copernicus EMS maps are compiled from multiple sensors at different wavelengths and polarisations. This improves the detection accuracy of Copernicus relative to single-wavelength and single-polarisation maps. Although the imagery was acquired on different days, combining both Sentinel 1 and Sentinel 2 images improved classification agreement (91\%; Table 6), underlining the complementary nature of the two Sentinel missions and emphasising the potential of Sentinel 2 data for both flood classification and map validation. In this instance, Sentinel 2 was better able to define flood extent based on apparent differences in NDWI values between flooded and non-flooded pixels.

Estimated flood depths were validated against a time series of river heights maintained by the OPW for the Shannon River Basin District (SRDB). Maximum river levels were recorded for 10 monitoring locations in the Shannon catchment, where flooding was recorded within a $500 \mathrm{~m}$ radius. Ordinary least squares linear regression was used to predict flood extent based on river gauge data. A significant relationship was found $(P=0.007)$, with an adjusted $R^{2}$ of 0.56 (Figure 11).
At two locations, flood maxima were within $25 \mathrm{~cm}$ of the measured river heights. The largest difference was at the Athlone station, where flood levels were overestimated by $9.70 \mathrm{~m}$. A Grubbs outlier test conducted using the "outliers" package in $\mathrm{R}$ (v.0.41) identified Athlone as a probable outlier $(G=2.09, U=0.45, P=0.075)$. Removing this station from the linear model increased the correlation to $0.85(P=0.006)$ and improved the $R^{2}$ value of the fitted model to $0.8(P<$ $0.001)$.

\section{Discussion}

\section{Flood extent}

Flooding is a common occurrence in Ireland, particularly in the Midlands, where the low gradient and poor flow capacity of many rivers lead to floods under typical winter weather (Charlton et al., 2006). Many Irish soils have a natural disposition towards saturation during winter months, or at any time under heavy rain, allowing surface ponding to develop. While there is an increase in the number of severe floods across Europe (Kundzewicz et al., 2013), flooding of the magnitude witnessed in winter 2015-2016 remains unusual in Ireland. A long-term, upward trend in the annual number of rain days and volume of precipitation will, however, likely see higher flood risk in the future (Kiely et al., 2009). In a study of future climate scenarios in terms of water supply and flooding, Charlton et al. (2006) predicted a probable increase in the magnitude and frequency of winter floods in the western half of Ireland before the end of this century in response to increased surface runoff.

Table 5. Accuracy assessment of Sentinel 1 flood map versus Copernicus EMS data

\begin{tabular}{|c|c|c|c|c|c|}
\hline \multirow{6}{*}{ 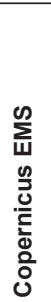 } & \multicolumn{5}{|c|}{ Sentinel 1 flood map } \\
\hline & & No flood & Flood & Total & User accuracy. \\
\hline & No flood & 37 & 1 & 38 & $97.4 \%$ \\
\hline & Flood & 17 & 33 & 50 & $66.0 \%$ \\
\hline & Total & 54 & 34 & 88 & \\
\hline & Producer accuracy. & $68.5 \%$ & $97.1 \%$ & & Overall accuracy $79.5 \%$ \\
\hline
\end{tabular}

Table 6. Accuracy assessment of combined Sentinel 1 and Sentinel 2 maps versus Copernicus EMS data

\begin{tabular}{|c|c|c|c|c|c|}
\hline \multirow{6}{*}{ 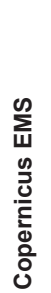 } & \multicolumn{5}{|c|}{ Combined Sentinel 1 and Sentinel 2 flood maps } \\
\hline & & No flood & Flood & Total & User accuracy \\
\hline & No flood & 31 & 7 & 38 & $81.6 \%$ \\
\hline & Flood & 1 & 49 & 50 & $98.0 \%$ \\
\hline & Total & 32 & 56 & 88 & \\
\hline & Producer accuracy & $96.9 \%$ & $87.5 \%$ & & Overall accuracy $91.0 \%$ \\
\hline
\end{tabular}




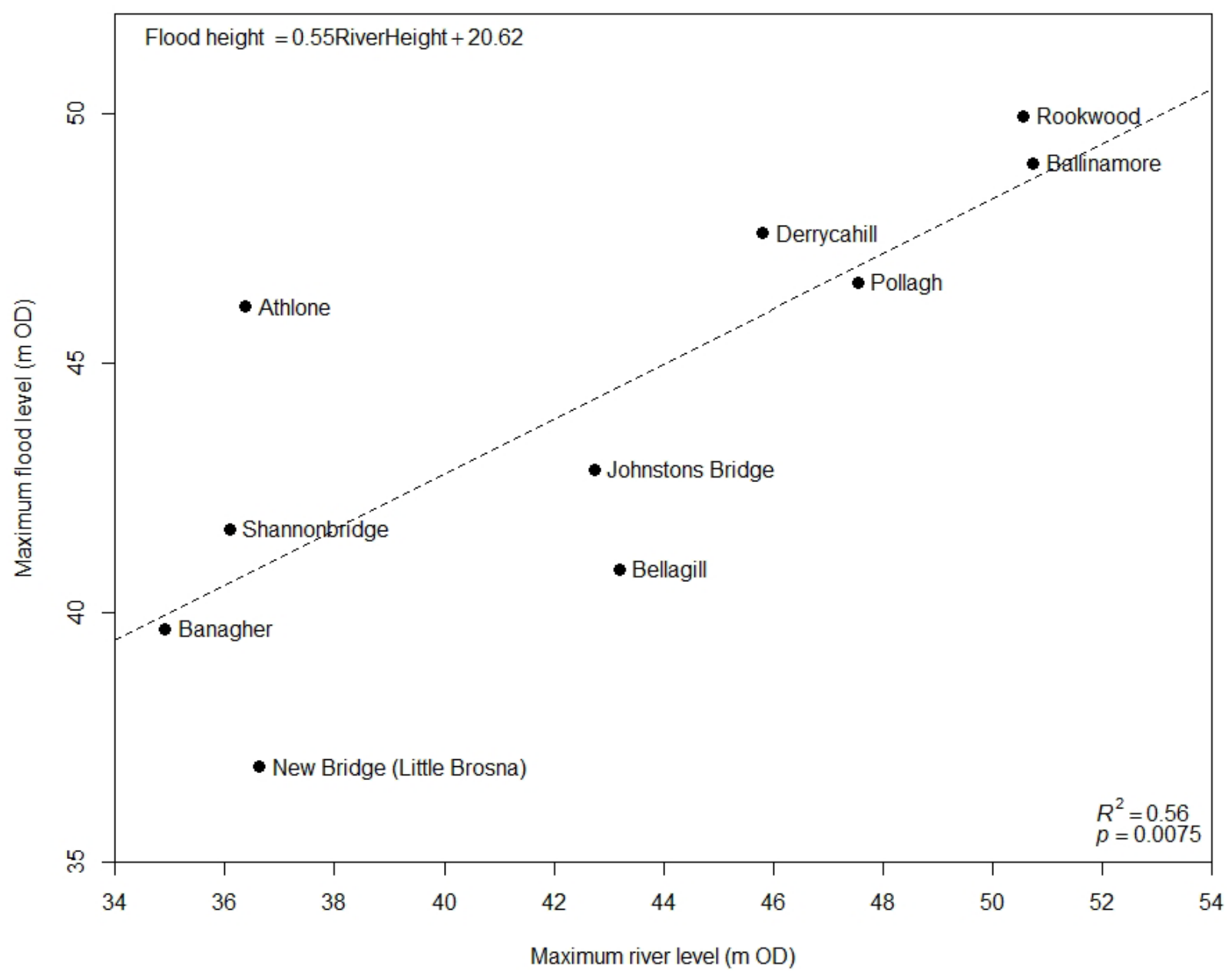

Figure 11. Relationship between estimated maximum flood levels and maximum river heights at 10 monitoring stations across the Shannon catchment. Flood heights are based on mean elevation values within $500 \mathrm{~m}$ of each station. Athlone is identified as an outlier (see text).

Approximately 24,356 ha were inundated between 19 November 2015 and 11 April 2016. Where misclassification errors were noted, they were predominantly from specular surfaces (e.g. airport runways, parking facilities and flat roofs) not removed by the masking process, although, in some instances, these could reflect actual cases of surface water. Higher accuracy in flood delineation would be expected had both Sentinel satellites been available at the time. Using both polarisations could also have increased accuracy (Twele et al., 2016). Clement et al. (2017) observed a strong linear association $\left(R^{2} 2\right.$ ( 0.87$)$ for Sentinel $1 \mathrm{VV}$ and $\mathrm{VH}$ backscatter. $\mathrm{VH}$ polarisation compensated for poor $\mathrm{VV}$ detection where surface water was roughened by the wind. It also improved flood identification as the area of inundation increased. VH can help in the identification of partially submerged fields
(Manjusree et al., 2012). Additional bands can allow more accurate segmentation of each scene. The thresholding method used in the paper was based on manually adjusting histograms to an appropriate grey level (Di Baldassarre et al., 2011). This method is widely used, fast and computationally efficient, but it is also labour intensive when the number of scenes is large. Twele et al. (2016) presented a fully automated processing chain designed for Sentinel flood detection and monitoring in near-real time ( $<45 \mathrm{~min}$ after new data are available at SciHub). Overall accuracies of $94 \%$ and $96.1 \%$ were reported for $\mathrm{VH}$ and $\mathrm{VV}$, respectively.

Unsurprisingly, the principal soils affected were riverine/ lacustrine sediments and clay-textured mineral soils with low infiltration capacity ( 9,525 ha). Pluvial flooding is proportional to antecedent soil moisture conditions (Reid and Parkinson, 
1984), and the flood extent had a significant response to total rainfall depth over several preceding days. The best explanatory model for flood extent was that for $5 \mathrm{~d}$ rainfall, which explained $51 \%$ of the variance in flood extent. In the short term, this likely reflects the rapid expansion of floods where rain was unable to infiltrate saturated or flooded soils. The continued significant effect over a more extended period may reflect the slow retreat of waters once an area was flooded (see Figure 2). Unusually high rainfall over the winter period maintained flood extents longer than would be normally expected. When soils are at field capacity or saturation, any further precipitation will lead to increased surface runoff. Infiltration-excess overland flow is triggered when the rainfall rate exceeds the infiltration capacity of a soil. It is rare but not unknown on Irish soils (Schulte et al., 2006), where it can happen at any time during the year (Doody et al., 2010). The risk is higher in winter, when the water infiltration rates can be as low as of $6.9 \times 10^{-8} \mathrm{~m} / \mathrm{s}(6 \mathrm{~mm} / \mathrm{d})$ on some soils (Diamond and Shanley, 2003). An example infiltration-excess pluvial flooding may be seen following intense rain over a 24-h period on 10-11 April (Met Éireann 2016c): 31-58 mm rain fell in $24 \mathrm{~h}$ in parts of the southwest, while stations in Dublin reported their wettest day in half a century. This rainfall was immediately reflected in a three-fold increase in flood area from 2,500 ha on 30 March to 7,600 ha flood on 11 April. Saturation-excess overland flow occurs when the rain falling onto saturated areas does not have a chance to infiltrate due to rising groundwater or the discharge of lateral subsurface flow, and runoff is initiated (Davie, 2008). Saturation-excess overland flow is mainly independent of rainfall intensity; instead, it is a factor of total rainfall and the soil and topographic factors. Areas prone to saturation expand and contract over different time scales as soil wetness increases (Hewlett and Hibbert 1967; Walter et al. 2000). This is the dominant type of overland flow generated under Irish conditions (Tunney et al., 2000). Pluvial flooding would have contributed to the flooding extent throughout the period. We can observe its impact on the 13 February map, when a steady period of flood contraction in January 2016 was reversed by persistent rain over several days. The result was a flood covering $\sim 19,357$ ha, only marginally smaller than the post-Storm Desmond maximum in mid-December. Other factors beyond rainfall likely contributed to the flood extent. At catchment scale, this may be drainage density (Schottler et al., 2014) or the level of arterial drainage (Harrigan et al., 2014). At smaller scales, flood persistence may reflect either differences in soil texture or the presence and design of artificial drainage systems (Wiskow and van der Ploeg, 2007).

Using the CORINE dataset, the greatest impact was on agricultural land, primarily grassland, which accounted for $\sim 50 \%$ of the flooded area. Both forestry and urban regions constituted $<1 \%$ each. In forested areas, this may be due to poor penetration of the canopy due to the C-band and VV polarisation used (Townsend, 2002). Longer wavelengths (L-band) and $\mathrm{HH}$ polarisation provide greater penetration into forest canopies (Wang et al., 1995). It may also reflect a mostly upland distribution of Irish forests (Upton et al., 2014), where extensive flooding would be unlikely to occur. Poor delineation in urban areas is generally a result of RADAR shadow caused by high buildings. These are areas that cannot be detected as the RADAR pulse is either obstructed from reaching them or reflected away (e.g. off flat or sloping surfaces, such as roofs). Flood mapping of urban environments requires higherresolution SAR and elevation data (Mason et al., 2012; Brown et al., 2016). This study concentrated on rural areas and did not seek to identify flooding in urban/forested regions specifically. Floods on areas of cut-over peat accounted for $\sim 7,000$ ha, which before reclamation, would have acted as hydrological sinks for excess surface water.

\section{Flood map uncertainty}

DEM uncertainty increases error propagation in hydrological and topographical modelling (Casas et al., 2006; Fisher and Tate, 2006; Weschler, 2007). Cook and Merwade (2009) demonstrated how flood inundation area was reduced with improved and increased resolution and accuracy in topographic data. To better quantify the vertical error that the DEM had on our estimates of depth and volume, a Monte Carlo simulation was used to estimate pixel-wise uncertainty across the map. Flood volume was determined with $95 \%$ certainty to be between $482,078,000 \mathrm{~m}^{3}$ and $575,648,500 \mathrm{~m}^{3}$. Estimate accuracy would have been considerably improved using a DEM with higher spatial resolution and a lower RMSE (from LIDAR and aerial photogrammetry), as demonstrated in several studies (Charlton et al., 2003; Lane et al., 2003; Mason et al., 2007; Schumann et al., 2009; Coveney and Roberts, 2017).

\section{Measuring post-flood recovery}

In many areas of the world, flooding, and the excessive soil moisture that accompanies it, can be a significant constraint on agricultural productivity (Schulte et al., 2012). Persistent waterlogging presents several challenges for farmers after surface waters subside. Excessive moisture can result in a collapse of soil aggregates (Hillel, 1998), and the subsequent loss of trafficability can harm farm operations (Vero et al., 2014). The elimination of air pores creates hypoxic conditions in the root zone, which is detrimental to plant health (Jackson and Colmer 2005). Studies have found a reduction in growth, leaf extension rate and chlorophyll concentrations of perennial ryegrass (Lolium perenne L.) following short-term waterlogging and submergence. For example, reduction in plant biomass was demonstrated by McFarland et al. (2003) after 14-21 d waterlogging. After $28 \mathrm{~d}$, laminae and root mass 
were reduced by up to $70 \%$ and photosynthesis was reduced by $30 \%-50 \%$.

Our findings indicated that the spring NDVI value for flooded pasture was lower when measured against non-flooded areas. NDVI values were only significantly different after the period of submergence exceeded eight flood events (96 d). There was no statistical difference in NDVI values for pixels flooded once up to eight times. After nine flood events (108 d), a significant decrease in NDVI value was recorded during the preceding period. This decline continued in subsequent days, with NDVI value after 10 flood events (120 d) becoming significantly lower again. This suggests that short-term waterlogging had little impact on spring NDVI. As flood duration increased, so too did the likelihood of flooding in late winter and early spring (February and early March). As the Sentinel 2 mission continues, its enhanced spectral resolution compared to Landsat 8 will be invaluable in monitoring postevent vegetation recovery. Sentinel 2 has three additional bands between $0.7 \mathrm{~mm}$ and $0.8 \mathrm{~mm}$ capable of detecting small changes in plant chlorophyll production (Delegido et al., 2011). At local scales $\left(<0.5 \mathrm{~km}^{2}\right)$, UAVs may provide greater flexibility in monitoring water-related stress and vegetation recovery when optical satellites cannot (Gago et al., 2015).

\section{Flood mapping in Ireland}

Considering the potential damage to rural areas from the rapid onset and delayed retreat of flood waters, the potential threat to rural communities and agricultural land should be investigated in future flood risk assessments. Expanding the ESA European Response Mechanism (ERM) to cover the whole country, and not just selected towns and their immediate hinterland, would offer essential support to rural communities. The primary benefit of expanding the ERM would be the access to several contributing satellite missions with different resolutions, polarisations and wavelengths, allowing the highest-possible accuracy for flood extent delineation (Martinis et al. 2016). It is ultimately, however, an emergency response mechanism intended to provide support under extraordinary conditions. This paper has demonstrated that freely available satellite data can be used to map flood extent and post-event recovery. Multispectral imagery (Sentinel 2) was better able to define flood extent based on apparent differences in spectral index values between flooded and non-flooded pixels. However, the all-weather capability of Sentinel 1 makes it a superior sensor for practical use under Irish conditions. Now fully operational, two Sentinel 1 satellites can acquire VV and VH polarised images every $6 \mathrm{~d}$. Fusion of SAR and optical data is well established, both for flood mapping and damage assessment (Pohl and van Genderen, 1998; Chaouch et al., 2011). In the study, combining the data from both Sentinel 1 and Sentinel 2 improved the overall classification accuracy, compared to Copernicus EMS approach. D'Addabbo et al. (2016) reported an overall flood classification accuracy of $96 \%$ using a fusion of data from SAR (COSMO-SkyMed) and multispectral images (RapidEye). For many areas, excessive cloud cover will limit the potential of optical data for flood mapping and damage assessment. Adopting a multisensor integration approach increases the likelihood of imaging flood extent when cloud contamination is low; however, there are integration issues between Landsat 8 and Sentinel 2 regarding differences in spectral bandwidth, which can affect data fusion (Mandanici and Bitelli, 2016; Flood, 2017).

When carried out initially, this study was the first national flood map prepared for Ireland using Sentinel 1 SAR. Sentinel provides an opportunity to monitor surface water and inundation levels at weekly intervals nationally. Flood maps have been developed in the past over smaller areas. For example, in response to flooding in 2009, Service Régional de Traitement d'Image et de Télédétection (SERTIT) mapped the Shannon catchment as part of the Strategies and Actions for Flood Emergency Risk Management (SAFER) programme (http://sertit.u-strasbg.fr/SITE_RMS/2009/18_rms_ irlande_2009/18_rms_irlande_2009.html). Currently, national flood mapping is based on records of historical flooding at 300 high-risk areas nationally. Flood maps prepared by the OPW (http://www.floodmaps.ie) are not designed or intended to monitor current events but rather to indicate the likelihood of a flood event occurring. The use of historical flood maps does not account for changing environmental factors (land cover, drainage etc.), which can vary significantly over time (de Moel et al., 2009). Remotely sensed flood maps could calibrate and validate historical flood maps while providing consistent, realtime mapping over large areas.

As flood magnitude and frequency increases, accurate flood maps can direct immediate emergency response to highrisk areas. In the longer term, detailed maps can direct Irish government capital spending on flood prevention, which is expected to increase to $€ 100$ million by 2021 in response to more-frequent and greater-magnitude flood events (National Directorate for Fire and Emergency Management, 2016). The Sentinel 1 map has demonstrated an ability to identify areas where flood waters persist for several weeks, as well as locations where buildings and infrastructure may be at risk. Accurate maps can also confirm damage to, or loss of property, for insurance claims and can allow insurers to determine the level of risk to rural homes and businesses (Galy and Sanders, 2002).

\section{Future directions}

The potential for mapping of national flood using Sentinel 1 has been demonstrated. The procedure followed guidelines laid down by the United Nations Office for Outer Space Affairs. The approach is robust and accurate and can serve as the basis for further nationwide mapping. Future maps could 
make use of both $\mathrm{VV}$ and $\mathrm{VH}$ polarisation. Greater automation will be required, and the approach of Twele et al. (2016) is promising. High-resolution topographic data will be essential to quantify flood depths and volumes accurately. The national mapping agency (OSI) is currently (summer 2017) laser scanning 185,000 ha nationally at high point density (https:// www.osi.ie/products/bluesky-aerial-imagery-lidar/blueskyireland). These elevation models will facilitate more accurate flood modelling. For national-scale modelling, however, the financial cost of acquiring high-resolution data can be prohibitive. Some European countries have recently taken steps to make national, or near-national, coverage of LIDAR elevation data freely available. The UK, e.g. provides free LIDAR-derived raster datasets at $0.25-2 \mathrm{~m}$ spatial resolution with a vertical accuracy of $\sim 5 \mathrm{~cm}$ (Environment Agency, https://data.gov.uk/dataset/lidar-composite-dsm-1m1). At small scales (several hundred hectares), high-resolution elevation data can be captured using imagery from UAVs to build surface models. UAV-derived DEMs have the capability of obtaining high spatial- and vertical-resolution data comparable to LiDAR data. Serban et al. (2016) and Coveney and Roberts (2017) have demonstrated the applicability of UAV-derived DEM in high-resolution flood modelling and prediction.

Flood extent was closely related to antecedent soil moisture. To accurately predict flood risk from either extreme weather events or the cumulative effects of prolonged precipitation on infiltration-impeded soils, accurate and timely data on soil moisture content are required (Brindlish et al., 2009). Currently, Irish soil moisture measurement is modelled using precipitation and evapotranspiration data from a small number of synoptic stations maintained by Met Éireann (Schulte et al., 2005; Schulte et al., 2015). Several studies have estimated antecedent soil moisture condition from remotely sensed soil moisture data (Pauwels et al., 2001; et al., 2010; Wanders et al., 2014). An integrated, multisensor (terrestrial and satellite) approach at field and catchment scales could allow for continuous monitoring and validation of independent soil moisture data using a distributed network of discrete soil moisture measurements (Ritsema et al., 2009; Nicolai-Shaw et al., 2015). Networking of ground-based proximal methods for estimating soil moisture can validate satellite-derived moisture estimates (Albergel et al., 2012). Proximal methods capable of estimating soil moisture over several hundred metres include cosmic-ray neutron probes (Robinson et al., 2008) and L-band reflectometry at global positioning system (GPS) ground stations (Larsson et al., 2008). The ability to monitor flood development in conjunction with hydrographic and meteorological data has excellent potential for flood prediction and mitigation in at-risk regions (van Dijk and Renzullo, 2011).

\section{Conclusions}

Sentinel 1 SAR images have been used to map the 2015-2016 winter floods in the Republic of Ireland. Map accuracy was validated against three independent sources (farm reports, optical flood map and RADAR flood map). There was $86 \%$ agreement between the reported flooding and farm reports. Lower accuracy between different satellite-derived flood maps probably reflected actual differences in flood height on different acquisition dates and under different weather conditions. Mapping accuracy could be improved using both available polarisations ( $\mathrm{VV}$ and $\mathrm{VH}$ ) on Sentinel 1 and through combining RADAR data with optical data where possible. The spatial resolution and vertical accuracy of the DEM used to determine flood depth and volume were not suited to extracting accurate flood metrics. Monte Carlo simulations were used to reduce potential measurement errors. However, flood depths were still overestimated by several metres in some areas. Both Sentinel missions have huge application potential to the Irish agricultural industry. For the local and national governments, they are an essential resource to map flooding and inform preventive strategies. For rural communities and businesses, these missions can map flood events and highlight (identify) at-risk areas. The effect of flooding on farming communities was demonstrated by identifying affected farm buildings. Longer effects of submergence and saturation were seen in multispectral images the following spring, whereby prolonged flooding had a significant impact on pasture growth. An integrated monitoring approach is necessary to identify problematic soils and catchments where high soil saturation not only drives flood magnitude but limits agricultural productivity. A fusion of existing remote and proximal sensing technologies could provide routine, nationwide soil moisture estimates under all conditions.

\section{Acknowledgements}

This paper was supported by the Teagasc Walsh Fellowship programme and was developed from a presentation at the 10th Irish Earth Observation Symposium in October 2016. The manuscript was significantly improved following comments from the editor and two anonymous reviewers.

\section{References}

Albergel, C., de Rosnay, P., Gruhier, C., Muñoz-Sabater, J., Hasenauer, S. Isaksen, L., Kerr, Y. and Wagner, W. 2016. Evaluation of remotely sensed and modelled soil moisture products using global ground-based in situ observations. Remote Sensing of Environment 180: 361-376. 
Amitrano, D., Di Martino, G., lodice, A., Mitidieri, F., Papa, M.N., Riccio, D. and Ruello, G. 2014. Sentinel-1 for monitoring reservoirs: a performance analysis. Remote Sensing 6: 10676-10693.

Arnesen, A.S., Silva, T.S.F., Hess, L.L., Novo, E.M.L.M., Rudorff, C.M., Chapman, B.D. and McDonald, K.C. 2013. Monitoring flood extent in the lower Amazon River floodplain using ALOS/PALSAR ScanSAR images. Remote Sensing of Environment 130: 51-61.

Bindlish, R., Crow, W.T. and Jackson, T.J. 2009. Potential role of passive microwave remote sensing in improving flood forecasts. IEEE Geoscience and Remote Sensing Letters 6: 112-116.

Bodoque, J.M., Guardiola-Albert, C., Aroca-Jiménez, E., Eguibar, M.Á. and Martínez-Chenoll, M.L. 2016. Flood damage analysis: first floor elevation uncertainty resulting from LiDAR-derived Digital Surface Models. Remote Sensing 8: 604.

Bolanos, S., Stiff, D., Brisco, B. and Pietroniro, A. 2016. Operational surface water detection and monitoring using Radarsat 2. Remote Sensing 8: 285.

Bourbigot, M., Johnsen, H. and Piantanida, R. 2016. Sentinel 1 product definition. Available online: https://sentinel.esa.int/documents/247904/1877131/Sentinel-1-Product-Definition [Accessed 25 August 2017], 129 pages.

Bourgeau-Chavez, L.L., Kasischke, E.S., Brunzell, S.M., Mudd, J.P., Smith, K.B. and Frick, A.L. 2001. Analysis of space-borne SAR data for wetland mapping in Virginia riparian ecosystems. International Journal of Remote Sensing 22: 3665-3687.

Brandt, S. 2005. Resolution issues of elevation data during inundation modelling of river floods. Proceedings of the 31st International Association of Hydraulic Engineering and Research Congress, Seoul, South Korea, pages 3573-3581.

Brivio, P.A., Colombo, R., Maggi, M. and Tomasoni, R. 2002. Integration of remote sensing data and GIS for accurate mapping of flooded areas. International Journal of Remote Sensing, 23: 429-441.

Brocca, L., Melone, F., Moramarco, T., Wagner, W., Naeimi, V. Bartalis, Z. and Hasenauer, S. 2010. Improving runoff prediction through the assimilation of the ASCAT soil moisture product. Hydrology and Earth System Sciences 14: 1881-1893.

Brown, K.M., Hambidge, C.H. and Brownett, J.M. 2016. Progress in operational flood mapping using satellite synthetic aperture RADAR (SAR) and airborne light detection and ranging (LiDAR) data. Progress in Physical Geography 40: 196-214.

Campbell, B.A. 2002. "Radar Remote Sensing of Planetary Surfaces". Cambridge University Press, London, 342 pages.

Carter, G.A. and Miller, R.L. 1994. Early detection of plant stress by digital imaging within narrow stress-sensitive wavebands. Remote Sensing of the Environment 50: 295-302.

Casas, A., Benito, G., Thorndycraft, V.R. and Rico, M. 2006. The topographic data source of digital terrain models as a key element in the accuracy of hydraulic flood modelling. Earth Surfaces, Processes and Landforms 31: 444-456.

Chaouch, N., Temimi, M., Hagen, S., Weishampel, J., Medeiros, S. and Khanbilvardi, R. 2011. A synergetic use of satellite imagery from SAR and optical sensors to improve coastal flood mapping in the Gulf of Mexico. Hydrological Processes 26: 1617-1628.

Charlton, M.E., Large, A.R.G. and Fuller, I.C. 2003. Application of airborne LiDAR in river environments: the River Coquet, Northumberland, UK. Earth Surface Processes and Landforms 28: 299-306.

Charlton, R., Fealy, R., Moore, S., Sweeney, J. and Murphy, C. 2006. Assessing the impact of climate change on water supply and flood hazard in Ireland using statistical downscaling and hydrological modelling techniques. Climatic Change 74: 475-491.

Chavez, P. S. 1996. Image-based atmospheric corrections - revisited and improved. Photogrammetric Engineering and Remote Sensing 62: 1025-1036.

Chen, Y., Huang, C., Ticehurst, C., Merrin, L. and Thew, P. 2013. An Evaluation of MODIS Daily and 8-day composite products for floodplain and wetland inundation mapping. Wetlands 33: 823835

Cialella, A.T., Dubayah, R., Lawrence, W. and Levine, E. 1997. Predicting soil drainage class using remotely sensed and digital elevation data. Photogrammetric Engineering and Remote Sensing 63: $171-178$

Clement, M.A., Kilsby, C.G. and Moore, P. 2017. "Multi-temporal synthetic aperture RADAR flood mapping using change detection". Available online: http://onlinelibrary.wiley.com/doi/10.1111/ jfr3.12303/pdf [Accessed 21 August 2017], 17 pages.

Congalton, R.G. and Green. K. 2008. "Assessing the Accuracy of Remotely Sensed Data: Principles and Practices". CRC Press, Boca Raton, 200 pages.

Cook, A. and Merwade, V. 2009. Effect of topographic data, geometric configuration and modeling approach on flood inundation mapping. Journal of Hydrology 377: 131-142.

Coveney, S. and Roberts, K. 2017. Lightweight UAV digital elevation models and orthoimagery for environmental applications: data accuracy evaluation and potential for river flood risk modelling. International Journal of Remote Sensing 38: 3159-3180.

D'Addabbo, A., Refice, A., Pasquariello, G., Lovergine, F.P. Capolongo, D. and Manfreda, S. 2016. A Bayesian network for flood detection combining SAR imagery and ancillary data. IEEE Transactions on Geoscience and Remote Sensing 54: 3612-3625.

Darnell, A.R., Tate, N.J. and Brunsdon, C. 2008. Improving user assessment of error implications in digital elevation models. Computers, Environment and Urban Systems 32: 268-277.

Davie, T. 2008. "Fundamentals of Hydrology". Routledge, New York, 200 pages

Delegido, J., Verrelst, J., Alonso, L. and Moreno, J. 2011. Evaluation of Sentinel-2 red-edge bands for empirical estimation of green LAI and chlorophyll content. Sensors 11: 7063-7081.

De Moel, H., van Alphen, J. and Aerts, J.C.J.H. 2009. Flood maps in Europe - methods, availability and use. Natural Hazards and Earth System Sciences 9: 289-301.

Di Baldassarre, D., Schumann, G., Brandimarte, L. and Bates, P. 2011. Timely low resolution SAR imagery to support floodplain modelling: a case study review. Surveys in Geophysics 32: 255269. 
Diamond, J. and Shanley, T. 2003. Infiltration rate assessment of some major soils. Irish Geography 36: 32-46.

Domeneghetti, A., Vorogushyn, S., Castellarin, A. Merz, B. and Brath, A. 2013. Probabilistic flood hazard mapping: effects of uncertain boundary conditions. Hydrology and Earth System Sciences 17: 3127-3140.

Doody, D.G., Higgins, A., Matthews, D., Foy, R.H., Pilatova, K., Duffy, O. and Watson, C.J. 2010. Overland flow initiation from a drained drumlin grassland hillslope. Soil Use and Management 26: 286298.

Du, Y., Zhang, Y., Ling, F., Wang, Q., Li, W., Li, X. Water Bodies' Mapping from Sentinel-2 imagery with modified Normalized Difference Water Index at 10-m spatial resolution produced by sharpening the SWIR band. Remote Sensing 8: 354.

Džubáková, K., Molnar, P., Schindler, K. and Trizna, M. 2015. Monitoring of riparian vegetation response to flood disturbances using terrestrial photography. Hydrology and Earth System Sciences 19: 195-208.

Fealy, R.M., Green, S., Loftus, M., Meehan, R., Radford, T., Cronin, C. and Bulfin, M. 2009. Teagasc EPA Soil and Subsoils Mapping Project-Final Report. Volume I. Teagasc. Dublin. Available online: https://t-stor.teagasc.ie/ [Accessed 10 November 2016].

Feng, Q., Liu, J. and Gong, J. 2015. Urban flood mapping based on Unmanned Aerial Vehicle remote sensing and Random Forest classifier-a case of Yuyao, China. Water 7: 1437-1455.

Fisher, P.F. and Tate, N.J. 2006. Causes and consequences of error in digital elevation models. Progress in Physical Geography 30: 467-489.

Flood, N. 2017. Comparing sentinel 2A and Landsat 7 and 8 using surface reflectance over Australia. Remote Sensing 9: 659.

Fu, Y.H., Piao, S., Zhao, H., Jeong, S-J., Wang, X., Vitasse, Y., Ciais, P. and Janssens, I.A. 2014. Unexpected role of winter precipitation in determining heat requirement for spring vegetation greenup at northern middle and high latitudes. Global Change Biology 20: 3743-3755.

Gago, J., Douthe, C., Gallego, P.P., Ribas-Carbo, M., Flexas, J., Escalon, J. and Medrano, H. 2015. UAVs challenge to assess water stress for sustainable agriculture. Agricultural Water Management 153: 9-19.

Galy, H. and Sanders, R.A. 2002. Using synthetic aperture radar imagery for flood modelling. Transactions in GIS 6: 31-42.

Gibson, P. 2000. "Introductory Remote Sensing Principles and Concepts”. Routledge, London, 216 pages.

Gstaiger, V., Huth, J., Gebhardt, S., Wehrmann, T. and Kuenzer, C. 2012. Multi-sensoral and automated derivation of inundated areas using TerraSAR-X and ENVISAT ASAR data. International Journal of Remote Sensing 33: 7291-7304.

Harrigan, S., Murphy, C., Hall, J., Wilby, R.L. and Sweeney, J. 2013. Attribution of detected changes in streamflow using multiple working hypotheses. Hydrology and Earth System Sciences Discussions 10: 12373-12416.

Hewlett, J.D. and Hibbert, A.R. 1967. Factors affecting the response of small watersheds to precipitation in humid regions. In: "Forest Hydrology" (eds. W.E. Sopper and H.W. Lull). Pergamon Press, New York, pages 275-290.

Hillel, D. 1998. "Environmental Soil Physics”. Academic Press, San Diego, 364 pages.

Heuvelink, G.B.M., Burrough P.A., and Leenaers, H. 1989. Propagation of errors in spatial modelling with GIS. International Journal of Geographical Information Systems 3: 303-322.

Horritt, M.S. 1999. A statistical active contour model for SAR image segmentation. Image and Vision Computing 17: 213-224.

Horritt, M.S., Mason, D.C., Cobby, D.M., Davenport, I.J. and Bates, P.D. 2003. Waterline mapping in flooded vegetation from airborne SAR imagery. Remote Sensing of the Environment 85: 271-281.

Huang, C., Nguyen, B.D., Zhang, S., Cao, S. and Wagner, W. 2017. A comparison of terrain indices toward their ability in assisting surface water mapping from Sentinel-1 data. ISPRS International Journal of Geo-Information 6: 140.

Insom, P., Cao, C., Boonsrimuang, P., Liu, D. Saokarn, A., Yomwan, P. and $\mathrm{Xu}, \mathrm{Y}$. 2015. A support vector machine-based particle filter method for improved flooding classification. IEEE Geoscience and Remote Sensing Letters 12: 1943-1947.

Jackson, M.B. and Colmer, T.D. 2005. Response and adaptation by plants to flooding stress. Annals of Botany 96: 501-505.

Ji, L., Zhang, L., Wylie, B.K. and Rover, J. 2011. On the terminology of the spectral vegetation index (NIR - SWIR)/(NIR+SWIR). International Journal of Remote Sensing 32: 6901-6909.

Johnston, P. "Turlough Database". Associated datasets and digital information objects connected to this resource are available at: Secure Archive for Environmental Research Data (SAFER) managed by Environmental Protection Agency Ireland. http://erc.epa. ie/safer/resource? id=61afb7df-3fa8-102a-b1da-b128b41032cc [Accessed 10 November 2016].

Joyce, K.E., Belliss, S.E., Samsonov, S.V., McNeill, S.J. and Glassey, P.J. 2009. A review of the status of satellite remote sensing and image processing techniques for mapping natural hazards and disasters. Progress in Physical Geography 33: 183-207.

Kiel, B., Alsdorf, D. and LeFavour, G. 2006. Capability of SRTM Cand X-band DEM data to measure water elevations in Ohio and the Amazon. Photogrammetric Engineering and Remote Sensing 72: 313-320.

Kiely, G., Leahy, P., Ludlow, F., Stefanini, B., Reilly, E. Monk, M., and Harris, J. 2009. "Extreme weather, climate and natural disasters in Ireland". Climate Change Research Programme 2007-2013. Report Series No. 5. Available online: https://www.epa.ie/pubs/ reports/research/climate/CCRP_5_Kiely_ExtremeWeather_syn_ web.pdf.pdf [Accessed 8 August 2017].

Kundzewicz, Z.W., Pińskwar, I. and Brakenridge, G.R. 2013. Large floods in Europe, 1985-2009. Hydrological Sciences Journal 58: $1-7$.

Kussul, N., Shelestov, A. and Skakun, S. 2011. Flood monitoring from SAR data. In "Use of Satellite and In-situ Data to Improve Sustainability" (eds. F. Kogan, A. Powell and O. Fedorov). NATO Science 
for Peace and Security, Series C: Environmental Security, pages 19-29.

Lane, S. N., James, T. D., Pritchard, H. and Saunders, M. 2003. Photogrammetric and laser altimetric reconstruction of water levels for extreme flood event analysis. The Photogrammetric Record 18: 293-307.

Lang, M.W. and Kasischke, E.S. 2008. Using C-band synthetic aperture RADAR data to monitor forested wetland hydrology in Maryland's coastal plain, USA. IEEE Transactions on Geoscience and Remote Sensing 46: 535.

Larson, K.M., Small, E.E., Gutmann, E.D., Bilich, A.L., Braun, J.J. and Zavorotny, V.U. 2008. Use of GPS receivers as a soil moisture network for water cycle studies. Geophysical Research Letters: Hydrology and Land Surface Studies 35: 1-5.

Leblanc, M., Lemoalle, J., Bader, J.C., Tweed, S. and Mofor, L. 2011. Thermal remote sensing of water under flooded vegetation: New observations of inundation patterns for the "Small" Lake Chad. Journal of Hydrology 404: 87-98.

Lee, J.S. 1983. Digital image smoothing and the sigma filter. Computer Vision, Graphics and Image Processing 24: 255-269.

LeFavour, G. and Alsdorf, D. 2005. Water slope and discharge in the Amazon River estimated using the shuttle RADAR topography mission digital elevation model. Geophysical Research Letters: Hydrology and Land Surface Studies 32:1-5.

Leon, J.X., Heuvelink, G.B.M. and Phinn, S.R. 2014. Incorporating DEM uncertainty in coastal inundation mapping. PLOS ONE 9: $1-12$.

Levine, E., Knox, R. and Lawrence, W. 1994. Relationships between soil properties and vegetation at the Northern Experimental Forest, Howland, Maine. Remote Sensing of Environment 47: 231-241.

Li, J. and Wong, D.W.S. 2010. Effects of DEM sources on hydrologic applications. Computers, Environment and Urban Systems 34: 251-261.

Long S., Fatoyinbo, T.E. and Policelli, F. 2014. Flood extent mapping for Namibia using change detection and thresholding with SAR. Environmental Research Letters 9: 35002-35009.

Lozano-Garcia, D., Fernandez, R. and Johannsen, C., 1991. Assessment of regional biomass-soil relationships using vegetation indexes. IEEE Transactions on Geosciences and Remote Sensing 29: 331-338.

Malenovský, Z., Rott, H.R., Cihlar, J., Schaepman, M.E., García-Santos, G., Fernandes, R. and Berger, M. 2012. Sentinels for science: Potential of Sentinel-1, -2, and -3 missions for scientific observations of ocean, cryosphere, and land. Remote Sensing of Environment 120: 91-101.

Mandanici, E. and Bitelli, G. 2016. Preliminary comparison of Sentinel-2 and Landsat 8 imagery for a combined use. Remote Sensing 8: 1014

Manfreda, S., Di Leo, M. and Sole, A. 2011. Detection of flood-prone areas using digital elevation models. Journal of Hydrological Engineering 10: 781-790.

Manjusree, P., Kumar, L.P., Bhatt, C.M., Rao, G.S. and Bhanumurthy,
V. 2012. Optimization of threshold ranges for rapid flood inundation mapping by evaluating backscatter profiles of high incidence angle SAR images. International Journal of Disaster Risk Science 3: 113-122.

Mansourpour, M., Rajabi, M.A. and Blais, J.A.R. 2006. Effects and performance of speckle noise reduction filters on active RADAR and SAR images. International Archives of the Photogrammetry and Remote Sensing and Spatial Information Science 36-1/W41: 1-6.

Martinis, S., Twele, A. and Voight, J. 2009. Towards operational near real-time flood detection using a split-based automatic thresholding procedure on high resolution TerraSAR-X data. Natural Hazards and Earth System Sciences 9: 303-314.

Martinis, S., Twele, A. and Voight, J. 2011. Unsupervised extraction of flood-induced backscatter changes in SAR data Using Markov image modelling on irregular graphs. IEEE Transactions on Geoscience and Remote Sensing 49: 251-263.

Martinis, S., Kuenzer, C., Wendleder, A., Huth, J., Twele, A., Roth, A. and Dech, S. 2015. Comparing four operational SAR-based water and flood detection approaches. International Journal of Remote Sensing 36: 3519-3543.

Mason, D.C., Horritt, M.S. Hunter, N.M. and Bates, P.D. 2007. Use of fused airborne scanning laser altimetry and digital map data for urban flood modelling. Hydrological Processes 21: 1436-1447.

Mason, D.C., Davenport, I.J., Neal, J.C., Schumann, G.J-P. and Bates, P.D. 2012. Near real-time flood detection in urban and rural areas using high-resolution synthetic aperture radar images. IEEE Transactions on Geoscience and Remote Sensing 50: 3041-3052.

Matgen, P., Schumann, G. Henry, J.B., Hoffmann, L. and Pfister, L. 2007. Integration of SAR-derived river inundation areas, high-precision topographic data and a river flow model toward near realtime flood management. International Journal of Applied Earth Observation and Geoinformation 9: 247-263.

Matgen, P., Hostache, R., Schumann, G., Pfister, L., Hoffmann, L. and Savenije, H.H.G. 2011. Towards an automated SAR-based flood monitoring system: Lessons learned from two case studies. Physics and Chemistry of the Earth 36: 241-252.

McFarlane, N.M., Ciavarella, T.A. and Smith, K.F. 2003. The effects of waterlogging on growth, photosynthesis and biomass allocation in perennial ryegrass (Lolium perenne L.) genotypes with contrasting root development. Journal of Agricultural Science 141: 241-248.

McFeeters, S.K. 1996. The use of normalized difference water index (NDWI) in the delineation of open water features. International Journal of Remote Sensing 17: 1425-1432.

Met Éireann. 2015. Spring (March, April and May 2015). Met Éireann, Glasnevin, Dublin.

Met Éireann. 2016a. Monthly Weather Bulletin No. 355, December 2015. Met Éireann, Glasnevin, Dublin.

Met Éireann. 2016b. Winter (December 2015, January 2016 and February 2016). Met Éireann, Glasnevin, Dublin.

Met Éireann. 2016c. Monthly Weather Bulletin No. 359, April 2016. Met Éireann. Glasnevin, Dublin. 
Michener, W.K. and Houhoulis, P.F. 1997. Detection of vegetation changes associated with extensive flooding in a forested ecosystem. Photogrammetric Engineering and Remote Sensing 63: 1363-1374.

Moran, M.S., Peters-Lidard, C.D., Watts, J.M. and McElroy, S. 2004. Estimating soil moisture at the watershed scale with satellitebased RADAR and land surface models. Canadian Journal of Remote Sensing 30: 805-826.

Musa, Z.N., Popescu, I. and Mynett, A. 2015. A review of applications of satellite SAR, optical, altimetry and DEM data for surface water modelling, mapping and parameter estimation. Hydrology and Earth System Sciences 19: 3755-3769.

National Directorate for Fire and Emergency Management. 2016. "Report on Flooding December 42015 - January 13 2016". Department of Housing, Planning, Community and Local Government. Available online: http://www.housing.gov.ie/sites/default/ files/publications/files/report_on_winter_2015-16_flooding.pdf [Accessed 24 August 2017], 95 pages.

Nicolai-Shaw, N., Hirschi, M., Mittelbach, H. and Seneviratne, S.I. 2012. Spatial representativeness of soil moisture using in situ, remote sensing and land reanalysis data. Remote Sensing of Environment 118: 215-226.

Otsu, N. 1979. A threshold selection method from grey-level histograms. IEEE Transactions on Systems, Man and Cybernetics 9: 62-66.

Ouma, Y.O. and Tateishi, R. 2006. A water index for rapid mapping of shoreline changes of five East African Rift Valley lakes: an empirical analysis using Landsat TM and ETM+ data. International Journal of Remote Sensing 27: 3153-3181.

Pantaleoni, E., Engel, A. and Johannsen, C.J. 2007. Identifying agricultural flood damage using Landsat imagery. Precision Agriculture 8: 27-36.

Pauwels, V.R.N., Hoeben, R., Verhoest, N.E.C. and De Troch, F.P. 2001. The importance of the spatial patterns of remotely sensed soil moisture in the improvement of discharge predictions for small scale basins through data assimilation. Journal of Hydrology 251: 88-102.

Pettorelli, N. 2014. The normalized difference vegetation index. Oxford University Press, London, 208 pages.

Pohl, C. and van Genderen, J.L. 1998. Review article Multisensor image fusion in remote sensing: Concepts, methods and applications. International Journal of Remote Sensing 19: 823-854.

Profeti, G. and Macintosh, H. 1997. Flood management through LANDSAT TM and ERS SAR data: A case study. Hydrological Processes 11: 1397-1408.

Puech, C. and Raclot, D. 2002. Using geographical information systems and aerial photographs to determine water levels during floods. Hydrological Processes 16: 1593-1602.

Rango, A. and Salomonson, V.V. 1974. Regional flood mapping from space. Water Resource Research 10: 473-484.

Reid, I. and Parkinson, R.J. 1984. The nature of the tile drain outfall hydrograph in heavy clay soils. Journal of Hydrology 72: 289-305.
Ritsema, C.J., Kuipers, H., Kleiboer, L., van den Elsen, E., Oostindie, K., Wesseling, J.G., Wolthuis J.W. and Having, P. 2009. A new wireless underground network system for continuous monitoring of soil water contents. Water Resources Research 45: W00D36.

Robinson, D.A., Campbell, C.S., Hopmans, J.W., Hornbuckle, B.K., Jones, S.B., Knight, R., Ogden, F., Selker, J. and Wendroth, O. 2008. Soil moisture measurement for ecological and hydrological watershed-scale observatories: A review. Vadose Zone Journal 7: 358-389.

Rodgers, J.C., Murrah, A.W. and Cooke, W.H. 2009. The impact of hurricane Katrina on the coastal vegetation of the weeks bay reserve, Alabama from NDVI Data. Estuaries and Coasts 32: 496507.

Sahoo, P.K., Soltani, S. and Wong, A.K.C. 1988. A survey of thresholding techniques. Computer Vision, Graphics, and Image Processing 41: 233-260.

Sanders, B.F. 2007. Evaluation of on-line DEMs for flood inundation modelling. Advances in Water Resources 30: 1831-1843.

Schmidt, G.L., Jenkerson, C.B., Masek, J., Vermote, E. and Gao, F. 2013. "Landsat ecosystem disturbance adaptive processing system (LEDAPS) algorithm description”. U.S. Geological Survey Open-File Report 2013-1057. Available online: https://pubs.usgs. gov/of/2013/1057/ofr13_1057.pdf [Accessed: 13 January 2017], 27 pages.

Schottler, S.P., Ulrich, J., Belmont, P., Moore, R., Lauer, J.W., Engstrom, D.R. and Almendinger, J.E. 2014. Twentieth century agricultural drainage creates more erosive rivers. Hydrological Processes 28: 1951-1961.

Schulte, R.P.O., Diamond, J., Finkele, K., Holden, N.M. and Brereton, A.J. 2005. Predicting the soil moisture conditions of Irish grasslands. Irish Journal of Agricultural and Food Research 44: 95-110.

Schulte, R.P.O., Simo, I., Creamer, R.E. and Holden, N.M. 2015. A note on the Hybrid Soil Moisture Deficit Model v2.0. Irish Journal of Agricultural and Food Research 54: 125-131.

Schulte, R.P.O., Richards, K., Daly, K., Kurz, I., McDonald, E.J. and Holden, N.M. 2006. Agriculture, meteorology and water quality in Ireland: a regional evaluation of pressures and pathways of nutrient loss to water. Proceedings of the Royal Irish Academy 106B: 117-133.

Schulte, R.P.O., Fealy, R., Creamer, R.E., Towers, W., Harty, T. and Jones R.J.A. 2012. A review of the role of excess soil moisture conditions in constraining farm practices under Atlantic conditions. Soil Use Management 28: 580-589.

Schumann, G., Bates, P.D. Horritt, M.S. Matgen, P. and Pappenberger, F. 2009. Progress in the integration of remote sensing-derived flood extent and stage data and hydraulic models. Reviews of Geophysics 47: RG4001.

Şerban, G., Rus, I., Vele, D., Breţcan, P., Alexe, M. and Petrea, D. 2016. Flood-prone area delimitation using UAV technology, in the areas hard-to-reach for classic aircrafts: case study in the northeast of Apuseni Mountains, Transylvania. Natural Hazards 82: 1817-1832. 
Steyer, G.D., Couvillion, B.R. and Barras, J.A. 2013. Monitoring vegetation response to episodic disturbance events by using multitemporal vegetation indices. Journal of Coastal Research 63: 118-130.

Townsend, P.A. 2002. Relationships between forest structure and the detection of flood inundation in forested wetlands using C-band SAR. International Journal of Remote Sensing 23: 443-460.

Tucker, C.J. 1979. Red and photographic infrared linear combinations for monitoring vegetation. Remote Sensing of Environment 8: $127-150$

Tunney, H., Coulter, B.S., Daly, K., Kurz, I., Coxon, C., Jeffrey, D., Mills, P., Kiely, G. and Morgan, G. 2000. Quantification of phosphorus loss from soil to water, End of Project Reports, Teagasc.

Twele A., Cao W.X., Plank S. and Martinis, S. 2016. Sentinel-1-based flood mapping: a fully automated processing chain. International Journal of Remote Sensing 37: 2990-3004.

UN-SPIDER Knowledge Portal. 2016. "Recommended Practice: Flood Mapping. Space-based Information for Disaster Management and Emergency Response", UN Office for Outer Space Affairs. Available online: http://www.un-spider.org/advisory-support/ recommended-practices/recommended-practice-flood-mapping [Accessed 21 August 2017].

Upton, V., O'Donoghue, C. and Ryan, M. 2014. The physical, economic and policy drivers of land conversion to forestry in Ireland. Journal of Environmental Management 132: 79-86.

van Dijk, A.I.J.M. and Renzullo, L.J. 2011. Water resource monitoring systems and the role of satellite observations. Hydrology and Earth System Science 15: 39-55.

Vero, S.E., Antille, D.L., Lalor, S.T.J. and Holden, N.M. 2014. Field evaluation of soil moisture deficit thresholds for limits to trafficability with slurry spreading equipment on grassland. Soil Use and Management 30: 69-77.

Walter, M.T., Walter, M.F., Brooks, E.S., Steenhuis, T.S., Boll, J. and Weiler, K. 2000. Hydrologically sensitive areas: Variable source area hydrology implications for water quality risk assessment. Journal of Soil and Water Conservation 3: 277-284.

Wanders, N., Karssenberg, D., de Roo, A., de Jong, S.M. and Bierkens, M.F.P. 2014. The suitability of remotely sensed soil moisture for improving operational flood forecasting. Hydrology and Earth System Sciences 18: 2343-2357.

Wang, Y. 2002. Mapping extent of floods: what we have learned and how we can do better. Natural Hazards Review 3: 68-73.

Wang, Y., Hess, L.L., Filoso, S. and Melack, J.M. 1995. Understanding the RADAR backscattering from flooded and non-flooded Amazonian forests: results from canopy backscatter modelling. Remote Sensing of Environment 54: 324-332.

Weschler, S.P. 2007. Uncertainties associated with digital elevation models for hydrologic applications: a review. Hydrological Earth System Sciences 11: 1481-1500.

Wechsler, S.P. and Kroll, C. 2006. Quantifying DEM uncertainty and its effects on topographic parameters. Photogrammetric Engineering and Remote Sensing 72: 1081-1090.

Wiskow, E. and van der Ploeg, R.R. 2003. Calculation of drain spacings for optimal rainstorm flood control. Journal of Hydrology 272 163-174.

Wu, S., Li, J. and Huang, G.H. 2008. A study on DEM-derived primary topographic attributes for hydrologic applications: Sensitivity to elevation data resolution. Applied Geography 28: 210-223.

Zandbergen, P.A. 2006. The effect of cell resolution on depressions in digital elevation models. Applied GIS 2: 1-35.

Zandbergen, P.A. 2011. Error propagation modeling for terrain analysis using dynamic simulation tools in ArcGIS model builder. In: "Geomorphometry 2011" (eds. T. Hengl, I.S. Evans, J.P. Wilson and M. Gould), pages 57-60.

Zhu, Z., Wang, S. and Woodcock, C.E. 2015. Improvement and expansion of the F-mask algorithm: cloud, cloud shadow, and snow detection for Landsat 4-7, 8, and Sentinel 2 images. Remote Sensing of Environment 159: 269-277. 